\title{
Application of the activated sludge model to aerated lagoons
}

\author{
GvR Marais, GA Ekama ${ }^{1 *}$ and MC Wentzel ${ }^{1}$ \\ 'Water Research Group, Department of Civil Engineering, University of Cape Town, Rondebosch, Cape South Africa
}

\begin{abstract}
The different kinds of aerated lagoons, which exclude anaerobic pre-treatment ponds, are described and the design approach for aerated lagoons is explained. This hinges around ensuring that the 1st lagoon is suspension mixed and the second and any additional are facultative. Selection of the retention time for the 1st lagoon is important to ensure complete utilization of the influent biodegradable organics. Minimum retention times to achieve this at $14^{\circ} \mathrm{C}$ and $22^{\circ} \mathrm{C}$ were determined with the general activated sludge kinetic simulation model for (i) readily biodegradable soluble organics (BSO) only, (ii) slowly biodegradable particulate organics (BPO) only, (iii) real municipal wastewater (20\% BSO and $80 \%$ BPO) and (iv) real municipal wastewater with $5 \% \mathrm{OHO}$ active VSS mass seed. The minimum hydraulic retention times for these four cases are: at $14^{\circ} \mathrm{C} 1.3,3.0,2.0$ and $1.5 \mathrm{~d}$, respectively, and at $22^{\circ} \mathrm{C} 0.3,2.0,1.2$ and $1.0 \mathrm{~d}$, respectively. From a comparison of the simulation results with the steady-state model calculations, washout of OHOs takes place at about $75 \%$ of these retention times. Approximate equations to estimate the power requirements for aeration by mechanical surface aerators and mixing are given. These equations are combined with those of the steady-state activated sludge lagoon model for calculating the oxygen requirements and the aeration power density $\left(\mathrm{W} / \mathrm{m}^{3}\right)$ in each lagoon. With these equations, it is shown that influent COD concentration needs to be between an upper and lower limit band to ensure that the $1^{\text {st }}$ lagoon is suspension mixed and the second lagoon is facultative. This COD concentration band decreases as the influent flow increases. The important conclusion arising from this is that if the aerated lagoon system is applied for small rural communities, where land for these large systems is likely to be available, then additional mixing energy above that for aeration will need to be provided to ensure that the 1st lagoon is suspension mixed - this additional aeration cost makes it unlikely that aerated lagoons will be applied for municipal wastewater treatment. Matching mixing and aeration power requirements for industrial organic wastewaters is easier because these usually are significantly stronger than municipal wastewaters.
\end{abstract}

\section{INTRODUCTION}

The lagoon system of wastewater treatment covers a spectrum of clearly definable systems differentiated by the degree of mixing and the method of oxygenation. At the one extreme is the oxidation pond, in which the mixing is totally dependent on natural conditions, mainly the wind, and oxygenation is almost entirely due to photosynthesis. The maximum load on the pond and its response to this is largely dictated by the prevailing environmental conditions. At the other extreme is the suspension mixed aerated lagoon, in which both mixing and oxygenation are provided by technological means which give the greatest degree of control over the system. Both the maximum loading and the response to this can be quantitatively estimated. Intermediate systems are defined by the degree of technological assistance with the mixing and oxygenation. On this basis 5 types of lagoon system can be identified, listed in increasing order of the amount of technological assistance applied for the required mixing and oxygenation:

(1) Oxidation ponds

(2) Mechanically assisted oxidation ponds

(3) Aerated oxidation ponds

(4) Facultative lagoons

(5) Suspension mixed aerated lagoons

\section{LAGOON SYSTEMS}

In order to bring some definition to the 5 types of lagoon system, the degree of aeration and mixing assistance in the different systems is briefly reviewed below.

*To whom all correspondence should be addressed

e-mail: george.ekama@uct.ac.za

Received 2 September 2016; accepted in revised form 17 March 2017

\section{Oxidation pond}

The oxidation pond has an extensive literature and it is not the objective to review the design procedure here. This is given by Gloyna (1971) and Marais (1966; 1970). Only the factors related to mixing and aeration will be briefly discussed.

When wastewater enters an oxidation pond, the settleable fraction of the organic load settles to the bottom of the pond where it forms a sludge layer. In this sludge layer, anaerobic fermentation takes place. As the sludge layer increases so does the fermentation until the accumulation of sludge in the layer equals the rate of sludge removal by fermentation. In this way, the sludge layer could achieve a steady state if environmental conditions remain unchanged. Fermentation in the sludge layer releases energy from the system in the form of methane gas, which escapes to the atmosphere. In this fashion, fermentation contributes significantly to the removal of energy (COD) from the wastewater. Marais $(1966 ; 1970)$ estimated that approximately 30 to $40 \%$ of influent energy leaves the system as methane gas. The depth of the sludge layer depends on the organic load per unit area of pond and the water temperature. The fermentation rate is very temperature dependent increasing as the temperature increases. Therefore, with seasonal temperature variations, the sludge layer depth also varies, increasing during the cold season (i.e. accumulating energy in the sludge layer) and decreasing during the hot season (reducing the energy in the sludge layer).

In the supernatant (upper) layers of the pond, algae develop, which, with photosynthesis, supply oxygen to the pond to facilitate heterotrophic breakdown of the non-settleable organics. In this way, aerobic conditions are maintained in the upper layers of the pond. The types of algae that grow and their concentrations are crucially affected by the mixing of the pond contents by wind action. If the mixing energy is 
low, stratification develops which prevents non-motile algae in the lower layers from being brought periodically to the photic surface layers. The non-motile algae therefore die out and are supplanted by motile algae which can move in and out of the photic zone independently of mixing. The non-motile algae are good oxygen producers whereas the motile algae are not. Also the density of the non-motile algae is greater than that of the motile algae. Consequently, during stratification, the oxygenation capacity of the pond is severely impaired, resulting in poor non-settleable organic material breakdown by the heterotrophic organisms. During windy and temperate weather, mixing is good and non-motile algae proliferate. This results in good oxygen generation and distribution throughout the water layers of the pond by the mixing action, and hence improved non-settleable organic material breakdown by the heterotrophic organisms. In general, mixing in the pond always has a marked beneficial influence on the ability of the pond to maintain aerobic conditions and sustain higher organic loading rates. Clearly, the sludge layer and mixing conditions of the pond have a crucial effect on the response of the pond under varying natural environmental conditions.

\section{Mechanically assisted oxidation ponds}

In order to overcome the adverse effects of (i) stratification on oxygen production, and (ii) increased loading on the pond supernatant by feedback from the sludge during the hot weather, the pond can be assisted to maintain non-motile algae in suspension by artificially augmenting the mixing action. This can be accomplished in small ponds by installing a recirculating pump giving a turnover of the pond volume once or twice per day. For large ponds ( $>10 \mathrm{ha}$ ) installation of a floating stirrer is preferable. These are similar to floating aerators but the blades are set deep below the pond surface and rotate slowly. The objective is to move large volumes of water at a slow velocity as this allows the mixing action to extend a considerable distance away from the stirrer. The energy requirement is small, $\sim 0.1 \mathrm{~W} /$ $\mathrm{m}^{3}$ pond volume. In Cape Town, a $10 \mathrm{~kW}$ floating stirrer on a 16 ha pond of $1 \mathrm{~m}$ depth $\left(0.6 \mathrm{~W} / \mathrm{m}^{3}\right)$ ensured complete mixing for extended periods over a $200 \mathrm{~m}$ radius. Comparison of the stirred pond with an identical unstirred adjacent pond indicated that there were higher oxygen concentrations, higher algal growth and improved visual appearance in the stirred pond.

Installation of stirring does not alter the basic physical/ biological processes in the pond. It only provides greater security for good non-motile algal growth by maintaining a minimum mixing level during those periods when the natural environmental conditions are such that stratification would develop in the pond. The presence and action of the sludge layer is in no way affected.

\section{Aerated oxidation ponds}

In this system, the natural oxygenation capacity of the oxidation pond is augmented by installing air pipelines with diffusers at regular intervals along the pond bottom. Sometimes the pipelines are raised above the bottom. The rising bubbles mix the pond contents and augment the oxygen supply, but the main source of oxygen remains algal photosynthesis. The mixing energy is insufficient to prevent settlement of settleable organic material from the influent and a sludge layer forms as in the oxidation pond. By raising the aeration pipes above the pond bottom, the sludge layer is not disturbed and fermentation can proceed unimpeded as in the oxidation pond.

The performance of aerated oxidation ponds has not been widely published in the open literature and design procedures tend to be in the hands of the aeration system manufacturers.

\section{Facultative aerated lagoons}

In the facultative aerated lagoon, oxygen is supplied wholly by artificial means, usually floating aerators. Algal photosynthesis plays little or no part in the oxygen supply. However, the mixing energy is insufficient to keep the settleable solids in suspension and a sludge layer forms on the pond bottom. There is relatively little accurate information available defining the level of energy required to ensure that the settleable solids remain in suspension, or to ensure that settlement will take place. Eckenfelder (1966) suggests that facultative conditions can be presumed to be present when the power density in the lagoon is $<2$ to $4 \mathrm{~W} / \mathrm{m}^{3}$ and suspension mixing is present at $>20 \mathrm{~W} / \mathrm{m}^{3}$. There is therefore a wide range of power inputs for which there is uncertainty regarding the type of mixing present in a lagoon. Yet it is important to know whether 'suspension mixed' or 'facultative' conditions are present in a lagoon because this affects the oxygen requirements and effluent quality from the lagoon.

A difficulty reported in the operation of facultative aerated lagoons is that foaming occurs. This tends to happen particularly where facultative lagoons are applied for the treatment of industrial wastewaters with high soluble $\mathrm{BOD}_{5}$ fractions. The reason for this is low mixing energy, so that the OHO active mass formed settles out with the result that aerobic degradation of organics in the lagoon supernatant layers is slowed. This type of foaming also occurs in activated sludge (AS) plants during start-up, when the organic load to OHO VSS ratio is very high.

\section{Suspension mixed aerated lagoons}

In this system, the aeration energy input is so high that no settlement of suspended solids takes place. Provided the lagoon is maintained in an aerobic state, the system is identical to the normal AS system except that (i) no settling tank and (ii) no sludge recycle are provided. Consequently, the sludge age $\left(R_{\mathrm{s}}\right)$ is equal to the hydraulic retention time $\left(R_{\mathrm{h}}\right)$. The effluent contains organic particulate material, mostly the AS formed from the influent organics, viz., active $\mathrm{OHO}\left(X_{\mathrm{BH}}\right)$, endogenous $\left(X_{\mathrm{E}}\right)$ and unbiodegradable particulate organics from the influent $\left(X_{\mathrm{I}}\right)$. From the COD balance, the reduction in COD between the unfiltered influent and effluent COD is equal to the carbonaceous oxygen demand for growth and endogenous respiration per unit influent flow. Generally speaking, this COD reduction is insufficient: The effluent COD is too high for unrestricted discharge to receiving stream and rivers. Additional treatment with the specific objective of removing the settleable solids from the effluent flow without settling tanks is necessary to achieve a reasonably good (though not nitrified) effluent quality.

Additional treatment is usually achieved in one or more oxidation ponds or facultative lagoons. In these second lagoons, the solids settle out to form a sludge layer and a relatively solidsfree effluent is obtained. The sludge in the layer ferments so that a considerable proportion of the influent energy is lost from the system via methane gas. Due to the fermentation, recycling of energy (COD) from the sludge layer to the supernatant layers occurs, imposing an oxygen demand in the supernatant. 
Therefore, the behaviour of the second facultative pond or lagoon does not at first sight appear to be different to the system where the suspension mixed lagoon is eliminated and the influent discharged directly to a facultative lagoon. However, there is a major difference. In the suspension mixed lagoon, the soluble and particulate organics are transformed to settleable solids by biological and physical processes such as growth, adsorption and flocculation. Most of the effluent organics are therefore settleable and settle out much more readily and completely in the second pond. The suspension mixed lagoon therefore acts as a biological 'flocculator', which promotes solid/ liquid separation in the subsequent facultative pond.

The oxygen demand in the suspension mixed lagoon can be calculated with good precision with the steady-state AS model as described in this paper. Also, by making the reasonable assumption that all the influent biodegradable organics are transformed to $\mathrm{OHO}$ active mass in the first suspension mixed lagoon, an accurate estimate of the upper limit of the oxygen demand in the subsequent facultative lagoon can also be made. This is done with the aid of the endogenous respiration part of the AS model and by assuming that the facultative pond is suspension mixed. Thus, by making the $1^{\text {st }}$ lagoon suspension mixed and assuming the second lagoon is also, it is possible to estimate with reasonable accuracy the oxygen demand for the $1^{\text {st }}$ lagoon and obtain an upper bound for the oxygen demand in the second facultative lagoon. It will be shown that in the $1^{\text {st }}$ lagoon the energy input from the surface aerator is sufficient to establish suspension mixing conditions whereas in the second lagoon it is not, with the result that facultative conditions are established in the second lagoon. The implications and merits of this approach are below.

\section{APPLICATION OF THE ACTIVATED SLUDGE MODEL TO SUSPENSION MIXED LAGOONS}

The design approach is based on two theories, (i) the steadystate activated sludge (AS) model and (ii) energy requirements for mixing. Assuming constant flow and load, and completely mixed conditions in the $1^{\text {st }}$ and second lagoons, allows application of the steady-state AS model to both. By assuming that all the influent biodegradable organics are utilized and transformed to OHO active VSS in the $1^{\text {st }}$ lagoon, it behaves very similarly to the single completely mixed AS system and the full growth-endogenous respiration AS model is applied to the design of the $1^{\text {st }}$ lagoon. With no growth of $\mathrm{OHO}$ biomass in the second lagoon, it behaves similarly to the in-series reactor waste activated sludge aerobic digester and only the endogenous respiration part of the AS model is applied to the design of the second (and additional) lagoons. As mentioned above, the energy requirements for suspension mixing and settlement of solids are not well defined, certainly not as well as for the AS model. Due to this uncertainty, it is difficult to specify definitive design criteria that accurately define the type of mixing. The mixing 'theory' included in the approach is based on some early empirical formulae and anecdotal data from the literature. However, the design approach is sound and as mixing 'theories' improve, these can be included in the design approach outlined below.

The aerated lagoon model in terms of COD is presented first, and thereafter in terms of $\mathrm{BOD}_{5}$. Recasting the design procedure in terms of $\mathrm{BOD}_{5}$ allows it to be used with the $\mathrm{BOD}_{5}$ as the energy measurement parameter. Most of the aerated lagoon performance data available in the literature are in terms of $\mathrm{BOD}_{5}$.
The design equations are therefore required in terms of $\mathrm{BOD}_{5}$ to validate the design approach.

\section{COD-BASED STEADY-STATE THEORY}

\section{The $1^{\text {st }}$ lagoon}

The same steady-state AS model equations of Marais and Ekama (1976) apply to the $1^{\text {st }}$ lagoon with sludge age $\left(R_{s}\right)$ equal to nominal hydraulic retention time $\left(R_{\mathrm{h}}\right)$, i.e., Eqs 1 to 8 below are obtained directly from their Eqs 43, 48, 53, 49, 30 and 31, 33, 32 and 51, respectively, with $R_{\mathrm{s}}=R_{\mathrm{h}}$ :

Influent biodegradable organics:

$S_{b i}=S_{t i}\left(1-f_{\text {S'up }}-S_{\text {S'us }}\right) \mathrm{mgCOD} / \mathrm{L}$

Influent unbiodegradable particulate organics (UPO):

$X_{I i}=S_{t i} \frac{f_{S / u p}}{f_{c v}} \mathrm{mgVSS} / \mathrm{L}$

Effluent unbiodegradable soluble organics (USO):

$S_{u s 1}=S_{u s i} \mathrm{mgCOD} / \mathrm{L}$

Effluent unbiodegradable particulate organics (UPO):

$X_{I 1}=X_{I i} \mathrm{mgVSS} / \mathrm{L}$

Effluent biodegradable organics:

$S_{b 1}=\frac{\left(1+b_{H T} R_{h 1}\right)}{K_{v} Y_{H} R_{h 1}}(5 \mathrm{a}): S_{b 1}=\frac{S_{b i}}{\left(1+K_{v} X_{B H} R_{h 1}\right)}(5 \mathrm{~b}) \mathrm{mgCOD} / \mathrm{L}$

Effluent OHO biomass:

$X_{B H 1}=\frac{Y_{H}\left(S_{b i}-S_{b 1}\right)}{\left(1+b_{H T} R_{h 1}\right)} \mathrm{mgVSS} / \mathrm{L}$

Effluent endogenous residue:

$X_{E 1}=f_{H} b_{H T} R_{h 1} X_{B H 1} \mathrm{mgVSS} / \mathrm{L}$

Effluent VSS:

$X_{v 1}=X_{B H 1}+X_{E 1}+X_{I i} \mathrm{mgVSS} / \mathrm{L}$

where:

$S_{b 1}=$ filtered effluent biodegradable COD concentration from the $1^{\text {st }}$ lagoon.

The remaining symbols are defined in the List of Symbols in Appendix 2. The subscripts 1 or $n$ denote the concentrations from the $1^{\text {st }}$ or $n^{\text {th }}$ lagoon. Because the lagoons are assumed suspension (or completely) mixed, the concentrations in the lagoon and its effluent are equal.

From the above, the unfiltered effluent COD concentration from the $1^{\text {st }}$ lagoon $S_{\mathrm{t} 1}$ is given by:

$S_{t 1}=S_{u s 1}+S_{b 1}+f_{c v} X_{v 1} \mathrm{mgCOD} / \mathrm{L}$

The filtered effluent COD concentration from the $1^{\text {st }}$ lagoon $S_{\mathrm{tf} 1}$ is given by:

$S_{t f 1}=S_{u s 1}+S_{b 1} \mathrm{mgCOD} / \mathrm{L}$ 
The carbonaceous oxygen demand in the $1^{\text {st }}$ lagoon $\left(F O_{c 1}, \mathrm{kgO} / \mathrm{d}\right.$ flux, Eq. 11) is found from Eq. 38 in Marais and Ekama (1976), i.e.

$F O_{c 1}=\left(1-f_{c v} Y_{H}\right) Q_{i}\left(S_{b i}-S_{b 1}\right)+f_{c v}\left(1-f_{H}\right) b_{H T} M X_{B H 1} \mathrm{mgO} / \mathrm{d}$

where:

$M X_{B H 1}=$ mass of OHO VSS in $1^{\text {st }}$ lagoon $X_{B H 1} V_{1} \mathrm{kgVSS}$

and $V_{1}=$ volume of the $1^{\text {st }}$ lagoon $R h_{1} Q_{1} \mathrm{ML}$

With regard to the values of the kinetic $\left(K_{\mathrm{v}}\right.$ and $\left.b_{\mathrm{H}}\right)$ and stoichiometric $\left(f_{\mathrm{H}}, f_{\mathrm{cv}}, Y_{\mathrm{H}}\right)$ constants, the same values for the AS system can be used. Of these, the only one of uncertain validity is the COD utilization rate $K_{\mathrm{v}}[\mathrm{L} /(\mathrm{mgOHOVSS} \cdot \mathrm{d})]$. It therefore may not give a very accurate estimate of the filtered effluent biodegradable COD concentration $\left(S_{b 1}\right)$ from the $1^{\text {st }}$ lagoon. However, this does not influence the design of the $1^{\text {st }}$ lagoon very much because $S_{\mathrm{b} 1}$, being soluble, is likely to be readily biodegradable and therefore very low (Marais and Ekama, 1976). More important is the unutilized biodegradable particulate organics (BPO) concentration to determine the concentration of biodegradable COD utilized in the lagoon. Being slowly biodegradable, this concentration will be significantly greater than $S_{\mathrm{b} 1}$. However, it cannot be measured because it is enmeshed with the AS and therefore part of the VSS concentration. For this reason, the design approach is based on prudent selection of the retention time (see below) to ensure a high soluble and particulate biodegradable COD utilization. Then the resulting carbonaceous oxygen demand (OD) will not be strongly influenced by the unutilized COD concentration. Whether the COD utilization is $95 \%$ or $98 \%$ in the $1^{\text {st }}$ lagoon, does not affect the carbonaceous OD very much - only by $3 \%$. If desired, the $K$ value determined by Marais and Ekama (1976) on AS systems treating municipal wastewater can be used, i.e.:

$K_{v T}=K_{v 20}(1.035)^{(T-20)} \mathrm{L} /(\mathrm{mgOHOVSS} \cdot \mathrm{d})$

where:

$K_{\mathrm{v} 20}=$ substrate utilization rate at $20^{\circ} \mathrm{C}=0.07 \mathrm{~L} /(\mathrm{mgOHOVSS} \cdot \mathrm{d})$

But it is far simpler to just ignore $K_{\mathrm{vT}}$ and assume $100 \%$ biodegradable COD utilization (i.e. $S_{\mathrm{b} 1}=0$ ) provided the hydraulic retention time $\left(R_{\mathrm{h} 1}\right)$ is correctly selected (see below).

For industrial wastewaters, the $K_{\mathrm{v}}$ value may be significantly different to that for municipal wastewaters but again this will not affect the design of the lagoon system very much, provided the retention time is not selected too low, because it focuses on supplying the correct mass of oxygen per day rather than on the accuracy of the effluent COD concentration.

\section{The $2^{\text {nd }}$ lagoon}

The effluent from the $1^{\text {st }}$ lagoon, containing $S_{\mathrm{b} 1}, X_{\mathrm{I} 1}, S_{\mathrm{us} 1}, X_{\mathrm{BH} 1}$, $X_{\mathrm{E} 1}$ and $X_{\mathrm{vl}}$, passes to the $2^{\text {nd }}$ lagoon with retention time $R_{\mathrm{h} 2}$. If $100 \%$ utilization of biodegradable COD was not assumed for the $1^{\text {st }}$ lagoon, then in the $2^{\text {nd }}$ lagoon, utilization of the influent biodegradable COD will be complete $\left(S_{\mathrm{b} 2}=0\right)$. Therefore, the concentrations of the variables in the $2^{\text {nd }}$ lagoon, and its effluent, are:

Effluent unbiodegradable soluble organics (USO):

$S_{u s 2}=S_{u s 1}=S_{u s i} \mathrm{mgCOD} / \mathrm{L}$
Effluent unbiodegradable particulate organics (UPO):

$X_{I 2}=X_{I 1}=X_{I i} \mathrm{mgVSS} / \mathrm{L}$

Effluent biodegradable organics:

$S_{b 2}=0 \mathrm{mgCOD} / \mathrm{L}$

Effluent OHO biomass:

$X_{B H 2}=\frac{Y_{H}\left(S_{b 1}\right)+X_{B H 1}}{\left(1+b_{H T} R_{h 2}\right)} \mathrm{mgVSS} / \mathrm{L}$

Effluent endogenous residue:

$X_{E 2}=X_{E 1}+f_{H} b_{H T} R_{h 2} X_{B H 2} \mathrm{mgVSS} / \mathrm{L}$

Effluent VSS:

$X_{v 2}=X_{B H 2}+X_{E 2}+X_{I 2} \mathrm{mgVSS} / \mathrm{L}$

From the above, the unfiltered effluent COD concentration from the $2^{\text {nd }}$ lagoon $S_{\mathrm{t} 2}$, if suspension mixed, is given by:

$S_{t 2}=S_{u s 2}+f_{c v} X_{v 2} \operatorname{mgCOD} / \mathrm{L}$

And, if facultative, is approximately equal to the filtered effluent COD concentration from the $2^{\text {nd }}$ lagoon $S_{\mathrm{t} 22}$, which is given by:

$S_{t f 2}=S_{u s 2}=S_{u s i} \mathrm{mgCOD} / \mathrm{L}$

The carbonaceous oxygen demand in the $2^{\text {nd }}$ lagoon $\left(F O_{c 2}\right.$, $\mathrm{kgO} / \mathrm{d}$ ) is like Eq. 11, except $S_{b i}$ is $S_{b 1}$, i.e.:

$F O_{c 2}=\left(1-f_{c v} Y_{H}\right) Q_{i}\left(S_{b 1}\right)+f_{c v}\left(1-f_{H}\right) b_{H T} M X_{B H 2} \mathrm{mgO} / \mathrm{d}$

where:

$M X_{B H 2}=$ OHO VSS mass in $2^{\text {nd }}$ lagoon $=X_{B H 2} V_{2}$ kgVSS

and $V_{2}=$ volume of the $2^{\text {nd }}$ lagoon $=R_{\mathrm{h} 2} Q_{\mathrm{i}} \mathrm{ML}$

\section{The $3^{\text {rd }}$ lagoon}

The effluent from the $2^{\text {nd }}$ lagoon, containing $X_{\mathrm{I} 2}, S_{\mathrm{us} 2}, X_{\mathrm{BH} 2}, X_{\mathrm{E} 2}$ and $X_{\mathrm{v} 2}$, passes to the $3^{\text {rd }}$ lagoon (if included) with retention time $R_{\mathrm{h} 3}$. In this lagoon, because utilization of biodegradable organics is complete, only endogenous respiration of the AS takes place (utilization of biodegradable organism organics). Therefore, the concentrations of the variables in the $3^{\text {rd }}$ lagoon, and its effluent (if completely mixed), are:

Effluent unbiodegradable soluble organics (USO):

$S_{u s 3}=S_{u s 2}=S_{u s 1}=S_{u s i} \mathrm{mgCOD} / \mathrm{L}$

Effluent unbiodegradable particulate organics (UPO):

$X_{I 3}=X_{I 2}=X_{I 1}=X_{I i} \mathrm{mgVSS} / \mathrm{L}$

Effluent biodegradable organics:

$S_{b 3}=0 \mathrm{mgCOD} / \mathrm{L}$ 
Effluent OHO biomass:

$X_{B H 3}=\frac{X_{B H 2}}{\left(1+b_{H T} R_{h 3}\right)} \mathrm{mgVSS} / \mathrm{L}$

Effluent endogenous residue:

$X_{E 3}=X_{E 2}+f_{H} b_{H T} R_{h 3} X_{B H 3} \mathrm{mgVSS} / \mathrm{L}$

Effluent VSS:

$X_{v 3}=X_{B H 3}+X_{E 3}+X_{I 3} \mathrm{mgVSS} / \mathrm{L}$

From the above, the unfiltered effluent COD concentration from the $3^{\text {rd }}$ lagoon $S_{\mathrm{t} 3}$ is given by:

$S_{t 3}=S_{u s 3}+f_{c v} X_{v 3} \mathrm{mgCOD} / \mathrm{L}$

The filtered effluent COD concentration from the $3^{\text {rd }}$ lagoon $S_{\mathrm{tf} 3}$ is given by:

$S_{t f 3}=S_{u s 3}=S_{u s i} \mathrm{mgCOD} / \mathrm{L}$

The carbonaceous oxygen demand in the $3^{\text {rd }}$ lagoon $\left(\mathrm{FO}_{\mathrm{c} 3}, \mathrm{kgO} / \mathrm{d}\right.$ flux) is like Eq. 22 but with no biomass growth, i.e.:

$F O_{c 3}=f_{c v}\left(1-f_{H}\right) b_{H T} M X_{B H 3} \mathrm{mgO} / \mathrm{d}$

where:

$M X_{B H 3}=$ OHO VSS mass in $3^{\text {rd }}$ lagoon $=X_{B H 3} V_{3} \mathrm{kgVSS}$

and $V_{3}=$ volume of the $3^{\text {rd }}$ lagoon $=R_{\mathrm{h} 3} Q_{\mathrm{i}} \mathrm{ML}$

\section{SELECTION OF RETENTION TIME}

To determine the effect of retention time on the degradation efficiency of the readily biodegradable soluble organics (BSO) and slowly biodegradable particulate organics (BPO), the general AS model (ASM1, Henze et al., 1987 or UCTOLD, Dold et al., 1991) was run for a single suspension mixed lagoon at a number of different retention times from 0.1 to $8 \mathrm{~d}$ at $14^{\circ} \mathrm{C}$ and $22^{\circ} \mathrm{C}$ with influents comprising (i) BSO only, (ii) BPO only, and the example raw wastewater in WRC (1984) (iii) with and (iv) without a 5\% (as COD) OHO VSS seed. All the runs were based on the default kinetic and stoichiometric constant values and the results are shown plotted in Figs 1a to h. Also shown in Fig. 1 are the steady-state (SS) lagoon model results assuming 100\% influent biodegradable COD utilization in the $1^{\text {st }}$ lagoon. From Figs la to h, the minimum retention time for (i) $\mathrm{OHO}$ washout (no biodegradable COD utilization) and (ii) equivalence with the steady-state model (> 95\% influent biodegradable COD utilization) are listed in Table 1.

From Figs $1 \mathrm{a}$ to $\mathrm{h}$ and Table 1, the following can be noted;

(1) At both temperatures, the BSO influent has the shortest washout retention time and the BPO influent the longest. The washout retention time for the raw wastewater, which comprises both BSO (25\%) and BPO (75\%), is (as expected) between the BSO and BPO influents washout retention times. The raw wastewater with the $5 \% \mathrm{OHO}$ seed does not have a washout retention time because $\mathrm{OHOs}$ are fed continuously into the lagoon with the influent resulting in at least some utilization of $\mathrm{BSO}$ and BPO depending on the retention time. The washout retention time for the raw wastewater is $1.4 \mathrm{~d}$ and $0.5 \mathrm{~d}$ at $14^{\circ} \mathrm{C}$ and $22^{\circ} \mathrm{C}$, respectively.
TABLE 1

Washout (zero biodegradable COD utilization, $\mathbf{R}_{\text {hmin }}$ ) and steady-state (SS) model equivalent ( $100 \%$ biodegradable COD utilization ( $R_{h} S S$ ) hydraulic retention times in days at 14 and $22^{\circ} \mathrm{C}$ for influents comprising BSO only, BPO only and raw wastewater (WW) with and without OHO ( $5 \%$ as COD) seed.

\begin{tabular}{|l|c|c|c|c|}
\hline \multirow{2}{*}{$\begin{array}{c}\text { Wastewater } \\
\text { (WW) type }\end{array}$} & \multicolumn{2}{|c|}{$\mathbf{1 4}^{\circ} \mathbf{C}$} & \multicolumn{2}{c|}{$\mathbf{2 2}^{\circ} \mathbf{C}$} \\
\cline { 2 - 5 } & $\mathrm{R}_{\mathrm{hmin}}(\mathbf{d})$ & $\mathrm{R}_{\mathrm{h}} \mathbf{S S}(\mathbf{d})$ & $\mathrm{R}_{\mathrm{hmin}}(\mathbf{d})$ & $\mathrm{R}_{\mathrm{h}}$ SS (d) \\
\hline BSO only & 1.1 & 1.3 & 0.2 & 0.3 \\
\hline Raw WW seed & - & 1.5 & - & 1.0 \\
\hline Raw WW & 1.4 & 2.0 & 0.5 & 1.2 \\
\hline BPO only & 1.7 & 3.0 & 1.3 & 2.0 \\
\hline
\end{tabular}

(2) The retention time for approximate equivalence with the steady-state model is longer than the washout retention time. For the BSO, the increase is very small - only 0.2 and 0.1 $\mathrm{d}$ at $14^{\circ} \mathrm{C}$ and $22^{\circ} \mathrm{C}$, respectively. For the $\mathrm{BPO}$, the increase is large -1.3 and $0.7 \mathrm{~d}$ at $14^{\circ} \mathrm{C}$ and $22^{\circ} \mathrm{C}$, respectively. Hence, the more easily the influent biodegradable organics are degraded, the smaller the difference between the washout and steadystate equivalent retention times. Like for the washout retention times, the steady-state equivalence retention time for the raw wastewater is between the BSO and BPO influent values, i.e., at $2.0 \mathrm{~d}$ and $1.2 \mathrm{~d}$ at $14^{\circ} \mathrm{C}$ and $22^{\circ} \mathrm{C}$, respectively. The steady-state equivalent retention time for raw wastewater with the $5 \% \mathrm{OHO}$ seed is somewhat lower at 1.5 and $1.0 \mathrm{~d}$ than that for the raw wastewater without $\mathrm{OHO}$ seed $(2.0 \mathrm{~d}$ and $1.2 \mathrm{~d})$.

From the above, it can be seen that if the retention time in the $1^{\text {st }}$ lagoon is selected longer than $2.0 \mathrm{~d}$ at $14^{\circ} \mathrm{C}$ and $1.2 \mathrm{~d}$ at $22^{\circ} \mathrm{C}$, virtually complete utilization of influent biodegradable organics will take place. Therefore, at retention times greater than these, the steady-state lagoon model assuming all the biodegradable organics are completely utilized can be applied to municipal wastewater without significant error. For other wastewaters, these minimum retention times may be different, depending on the biodegradability of the organics in the wastewater.

\section{OVERALL LAGOON PERFORMANCE}

Even if biodegradation of the influent biodegradable organics is virtually complete in the $1^{\text {st }}$ lagoon, the COD removal is still low. This is because the AS formed in the $1^{\text {st }}$ lagoon is part of the unfiltered effluent COD (Eq. 9) because the lagoon is suspension mixed. In fact, the power input of the aeration system in the $1^{\text {st }}$ lagoon, sized to supply the growth and endogenous oxygen demands (Eq. 11), is usually sufficient for suspension mixing. The filtered effluent COD is very low because (depending on the wastewater type and retention time) most of the influent biodegradable soluble organics (BSO) are utilized and transformed to OHO VSS mass (Eqs 5 and 6). In most wastewaters, including municipal wastewater, the $\mathrm{BSO}$ are readily biodegradable and $\mathrm{OHO}$ mass is produced very rapidly from it. This $\mathrm{OHO}$ mass accelerates the utilization of the slowly biodegradable particulate organics (BPO), but that not utilized in the retention time of the $1^{\text {st }}$ lagoon is enmeshed with the AS and so is removable by settlement (or filtration) in the $2^{\text {nd }}$ lagoon. This is the main purpose of the $2^{\text {nd }}$ (and $3^{\text {rd }}$ facultative) lagoon. In fact, the power input of the aeration system in the $2^{\text {nd }}$ (and $3^{\text {rd }}$ ) lagoon, sized to supply mainly the endogenous oxygen demand (Eqs 22 and 31), is usually insufficient for suspension mixing, even though the oxygen demand in it is calculated assuming 

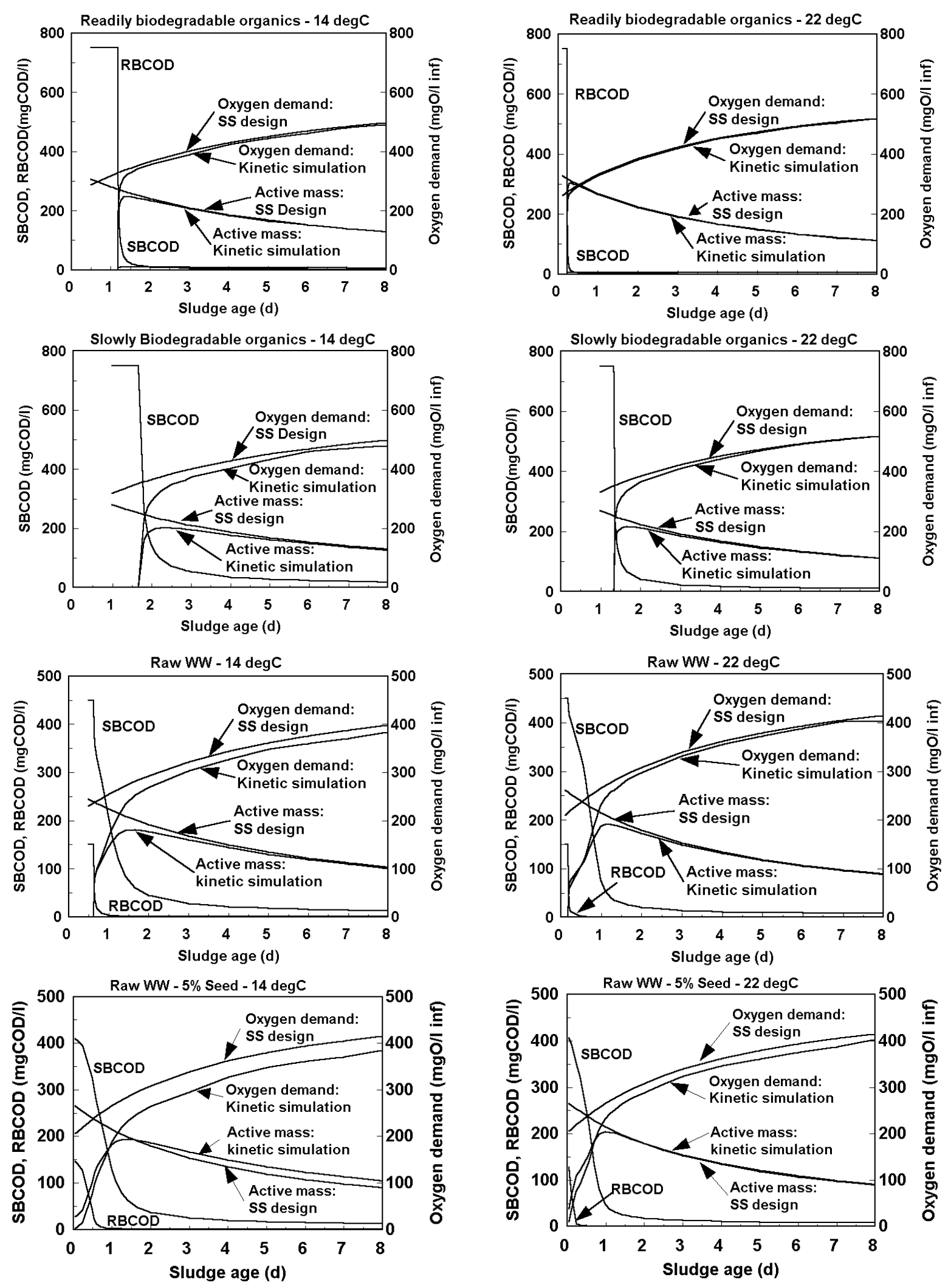

Figure 1

Readily biodegradable soluble organics (BSO, RBCOD), slowly biodegradable particulate organics (BPO, SBCOD) and OHO active COD concentrations versus retention time predicted by the general AS model (ASM No1:Henze et al., 1987 or UCTOLD: Dold et al., 1991) and the steady-state (SS) aerated lagoon model with $100 \%$ biodegradable COD utilization for a single suspension mixed lagoon at $14^{\circ} \mathrm{C}$ (left) and $22^{\circ} \mathrm{C}$ (right) with influents comprising (i) BSO (RBCOD) only (Figs 1a and b, top), (ii) BPO (SBCOD) only (Figs 1c and d, middle upper), and the example raw WW (iii) without (Figs 1 e and f, middle lower) and (iv) with a 5\% (as COD) OHO VSS seed (Figs $1 \mathrm{~g}$ and $h$, bottom). 
complete mixing. The unfiltered effluent COD from the $2^{\text {nd }}$ (and $3^{\text {rd }}$ ) lagoons is therefore mainly the COD of the remaining nonsettleable AS (which is small) and the unbiodegradable soluble organics (USO) (Eqs 21 or 30). The COD of filtered effluent is mainly the COD of the USO (Eqs 21 or 30).

\section{COD BALANCE OVER THE LAGOON SYSTEM}

Each lagoon in the system, as well as the system overall, must conform to the COD balance. The COD balance up to and including the $n^{\text {th }}$ lagoon is given by;

$Q_{i} S_{t i}=Q_{i} S_{t n}+\sum_{1}^{n} F O_{c n} \mathrm{kgCOD} / \mathrm{d}$

where:

$Q_{i} S_{t i}=$ COD load applied to system $(\mathrm{kgCOD} / \mathrm{d})$

$S_{t n}=$ unfiltered COD concentration from the $n^{\text {th }}$ lagoon

mgCOD/L (Eqs 9, 20 and 29)

$\sum F O_{\text {cn }}=$ flux OD up to and including the $n^{\text {th }}$ lagoon $(\mathrm{kgO} / \mathrm{d}, \mathrm{Eqs}$ 11,22 and 31).

It should be noted that the COD removal and the COD degraded are equal only for the $1^{\text {st }}$ lagoon because this is the only lagoon that is suspension mixed. With settlement of AS in the facultative $2^{\text {nd }}$ (and $3^{\text {rd }}$ ) lagoons, the COD removal is much greater than the COD degraded, both of which are difficult to estimate because they depend on the environmental conditions in the lagoons. The COD degraded depends on the fermentation rate in the sludge layer and the COD removal on the efficiency of AS settling.

\section{STEADY-STATE MODEL APPLICATION}

The theory set out above can be applied to raw municipal wastewater without difficulty. This is because the unbiodegradable soluble and particulate COD fractions $\left(f_{\text {Sus }}\right.$ and $f_{\text {Sup }}$ ) are fairly well known (WRC, 1984). When applying the theory to specific industrial wastewaters, the problem is that these wastewater characteristics are not known. To determine these two characteristics for a particular industrial wastewater requires an experimental investigation in which two or more AS systems treating the particular wastewater are operated at different sludge ages for an extensive period (about 6 months). At present, there are not many industrial wastewaters that have been characterized in this way in terms of COD. There is far more operating experience with municipal and industrial wastewater treatment in aerated lagoons in terms of $\mathrm{BOD}_{5}$.

Therefore, the steady-state aerated lagoon model equations developed above in terms of COD are transformed to $\mathrm{BOD}_{5}$ units below to give some validation of the model. Interestingly, the use of $\mathrm{BOD}_{5}$ leads to a simple aerated lagoon design procedure and provides insight into their behaviour because the biological processes in the BOD bottle on an unfiltered effluent from the $n^{\text {th }}$ lagoon are the same as in the $(n+1)^{\text {th }}$ lagoon - i.e. mainly endogenous respiration.

\section{BOD $_{5}$-BASED THEORY}

The main difference when using the $\mathrm{BOD}_{5}$ as the wastewater strength parameter instead of the $\mathrm{COD}$, is that the $\mathrm{BOD}_{5}$ is related, in a non-linear way, only to the oxygen consumed in the utilization of the biodegradable organics through the growth and endogenous respiration processes (see Appendix 1 for detail).
Initially in the BOD test, oxygen is utilized for growth of $\mathrm{OHO}$ VSS (catabolism) on the biodegradable organics in the sample and thereafter in the utilization of the biodegradable organics of the OHO VSS via endogenous respiration.

The unfiltered influent $\mathrm{BOD}_{5}$ is the oxygen utilized for growth of OHO VSS on the biodegradable organics in the influent wastewater and for endogenous respiration of this $\mathrm{OHO}$ VSS over $5 \mathrm{~d}$. The $\mathrm{BOD}_{5}$ gives no indication of the unbiodegradable organics in the effluent, which in some industrial wastewaters can be considerable. From Eq. A13 in Appendix 1, the influent $\mathrm{BOD}_{5}$ and biodegradable COD $\left(S_{\mathrm{bi}}\right)$ are related proportionally for a particular wastewater. If the proportionality factor is $\gamma$, then the biodegradable $\operatorname{COD}\left(S_{\mathrm{bi}}\right)$ from a measured $\mathrm{BOD}_{5}$ is:

$$
S_{b i}=\gamma \mathrm{BOD}_{5 i} \mathrm{mgCOD} / \mathrm{L}
$$

The magnitude $\gamma$ is related to the rate of utilization of the wastewater organics in the $\mathrm{BOD}_{5}$ test (i.e. the $\mathrm{K}$ rate in $\mathrm{Eq}$. A14), which in turn is related to the proportion of BSO in the wastewater. However, if $\gamma$ values for different wastewaters are known, it is possible to use the $\mathrm{BOD}_{5}$ parameter in the CODbased design equations developed above.

The $\mathrm{BOD}_{5}$ in the unfiltered effluent from a suspension mixed lagoon is oxygen utilization due to two effects, i.e. (i) growth of $\mathrm{OHO}$ mass on the residual influent biodegradable organics and (ii) endogenous respiration of the OHO VSS in the effluent and that produced in the test. The unfiltered effluent $\mathrm{BOD}_{5}$ from the $1^{\text {st }}$ lagoon therefore is similar to the carbonaceous oxygen demand in the $2^{\text {nd }}$ lagoon (Eq. 22). In fact, the biological processes in the $\mathrm{BOD}_{5}$ test are simply a continuation of those in the $1^{\text {st }}$ lagoon.

The remaining BSO can be measured on the filtered effluent $\mathrm{BOD}_{5}$. However, there is no way of knowing how much of the unfiltered effluent $\mathrm{BOD}_{5}$ concentration is due to undegraded $\mathrm{BPO}$ enmeshed in the AS. Being slowly biodegradable, the BPO concentration can be high at low retention times $(<1 \mathrm{~d}$, see Figs $1 \mathrm{e}$ and $\mathrm{f}$ ). However, it is not necessary to have a very accurate value because it is usually very low for $R_{h}>1.5 \mathrm{~d}$. At $R_{h}>1.5$ $\mathrm{d}$, most of the biodegradable organics, whether readily (BSO) or slowly (BPO) biodegradable, will have been utilized and so usually can be neglected without much error in the estimate of the carbonaceous oxygen demand, especially if the influent $\mathrm{BOD}_{5}$ is high (see Figs 1 e and $\mathrm{f}$ ).

Accepting that the remaining influent biodegradable organics concentration in the lagoon effluent is zero, then from Eq. A9, with $S_{b i}=0$ and $t=5 \mathrm{~d}$, the unfiltered effluent $\mathrm{BOD}_{5}$ from the $n^{\text {th }}$ lagoon is:

$\mathrm{BOD}_{5 n}=f_{c v}\left(1-f_{H}\right) X_{B H n}\left(1-e^{0.24 \times 5}\right)=0.827 X_{B H n} \mathrm{mgO} / \mathrm{L}$

Note from Eq. 34 that, even though all the influent biodegradable organics have been utilized, the effluent $\mathrm{BOD}_{5}$ is not zero. This is because endogenous respiration of the OHO VSS continues in the $\mathrm{BOD}_{5}$ test.

\section{The $1^{\text {st lagoon }}$}

The same steady-state AS model equations based on COD apply. If required, the filtered effluent $\mathrm{BOD}_{5 \mathrm{fl}}$, can be calculated from:

$\mathrm{BOD}_{5 n}=\frac{\gamma\left(1+b_{H T} R_{h 1}\right)}{K_{v B} Y_{H B} R_{h 1}} \mathrm{mgBO}_{5} / \mathrm{L}$ 
The $\mathrm{BOD}_{5}$ utilized, $\triangle \mathrm{BOD}_{5}$, is the difference between the influent and effluent $\mathrm{BOD}_{5}$, i.e :

$\Delta \mathrm{BOD}_{5}=\mathrm{BOD}_{5 i}-\mathrm{BOD}_{5 f 1} \approx \mathrm{BOD}_{5 i} \operatorname{mgBOD}_{5} / \mathrm{L}$

and hence from Eq. 6, the active organism concentration is:

$X_{B H 1}=\frac{Y_{H} \gamma \Delta \mathrm{BOD}_{5 i}}{\left(1+b_{H T} R_{h 1}\right)} \mathrm{mgVSS} / \mathrm{L}$

where:

$\mathrm{BOD}_{5 \mathrm{i}}=$ influent $\mathrm{BOD}_{5}$ concentration $(\mathrm{mg} / \mathrm{L})$

$\mathrm{BOD}_{5 \mathrm{fl}}=$ filtered effluent $\mathrm{BOD}_{5}(\mathrm{mg} / \mathrm{L})$

Equations 35 to 37 are correct for purely soluble organic wastewaters. For wastewaters that include particulate biodegradable organics, these equations are only approximate because $\triangle \mathrm{BOD}_{5}$ does not correctly reflect the influent biodegradable organics utilized - the concentration of unutilized particulate biodegradable organics enmeshed in the VSS solids is not known.

Because the $\mathrm{BOD}_{5}$ gives no estimate of the influent unbiodegradable particulate organics concentration (UPO, $S_{\text {upi }}$ or $\left.X_{\mathrm{Ii}}\right)$, the VSS concentration in the lagoon cannot be calculated.

The mass of OHO VSS in the $1^{\text {st }}$ lagoon is given by:

$M X_{B H}=Q_{i} R_{h 1} X_{B H 1} \mathrm{kgVSS}$

and hence the carbonaceous oxygen demand in the $1^{\text {st }}$ lagoon $\left(F O_{c 1}, \mathrm{kgO} / \mathrm{d}\right)$ is found from Eq. 11, i.e.:

$F O_{c 1}=\gamma\left(1-f_{c v} Y_{H}\right) Q_{i}\left(\Delta B O D_{5}\right)+f_{c v}\left(1-f_{H}\right) b_{H T} M X_{B H 1} \mathrm{mgO} / \mathrm{d}$

From Eq. 34 , the $\mathrm{BOD}_{5}$ of the unfiltered effluent, $\mathrm{BOD}_{51}$, is given by:

$\mathrm{BOD}_{51}=\mathrm{BOD}_{5 f 1}+0.827 X_{B H 1} \mathrm{mgO} / \mathrm{L}$

The equations above work best when $\mathrm{BOD}_{5 \mathrm{f} 1}=0$ so that $\triangle \mathrm{BOD}_{5}$ $=\mathrm{BOD}_{5 \mathrm{i}}$, and hence it is recommended to select retention times at which there is reasonable certainty that this is so (see Fig 1a to $\mathrm{h}$ and Table 1).

With regard to the values of the kinetic $\left(K_{v B}\right.$ and $\left.b_{H}\right)$ and stoichiometric $\left(f_{H}, f_{c v}, Y_{H B}\right)$ constants, only $K_{v B}$ and $Y_{H B}$ are different and the $\mathrm{BOD}_{5}$-based values can be calculated from the COD-based values. Converting the filtered effluent biodegradable $\operatorname{COD}\left(S_{b 1}\right.$, Eq. 5) to $\mathrm{BOD}_{5}\left(\mathrm{BOD}_{5 f 1}\right.$, Eq. 35) with Eq. A12 yields:

$\mathrm{BOD}_{5 f 1}=0.707 S_{b i} \mathrm{mgBOD}_{5} / \mathrm{L}$

Also, the yield coefficient in terms of $\mathrm{BOD}_{5}$ is obtained from:

$Y_{H} S_{b i}=Y_{H B} \mathrm{BOD}_{5 i}$

where $Y_{H B}=y Y_{H}$ and $\mathrm{y}$ is the $\mathrm{COD} / \mathrm{BOD}_{5}$ ratio of the influent wastewater. With $Y_{H}=0.45 \mathrm{mgVSS} / \mathrm{mgCOD}$ yields $Y_{H B}=0.81$ $\mathrm{mgVSS} / \mathrm{mgBOD} 5$ for $\gamma=1.8$ for municipal wastewater.

Hence, setting Eqs 5a and 35 equal, yields:

$K_{v B}=K_{v} 0.707=0.055 \mathrm{~L} /(\mathrm{mgVSS} . \mathrm{d})$
Substituting 0.81 for $Y_{\mathrm{HB}}$ and 0.055 for $K_{\mathrm{vB}}$ into Eq. 35 yields the $\mathrm{BOD}_{5}$ equivalent (from Eq. A12) of $S_{\mathrm{b} 1}$ in Eq. 5.

Of the $Y_{H B}$ and $K_{v B}, K_{v B}$ is of uncertain validity for the same reasons that $K_{v}$ is uncertain. It therefore may not give accurate estimates of the filtered effluent $\mathrm{BOD}_{5}$ concentration from the $1^{\mathrm{s}}$ lagoon. However, like $K_{v}$, this does not influence the design of the $1^{\text {st }}$ lagoon very much because (i) a retention time is selected so that the residual soluble and particulate (enmeshed with the VSS) biodegradable organics are very low and (ii) the design approach is based on the carbonaceous OD which is not strongly influenced by the residual biodegradable organics concentration, especially if the influent $\mathrm{BOD}_{5}$ is high. But, if required, the $K_{v B}$ value, determined from the effluent soluble COD concentration from AS systems treating municipal wastewater, can be used, i.e.:

$K_{v B T}=K_{v B 20}(1.035)^{(T-20)} \mathrm{L} /(\mathrm{mgVSS} \cdot \mathrm{d})$

where:

$K_{\mathrm{vB} 20}=$ substrate utilization rate at $20^{\circ} \mathrm{C}$

$=0.055 \mathrm{~L} /(\mathrm{mgVSS} \cdot \mathrm{d})$

For industrial wastewaters, the $K_{\mathrm{vB}}$ value may be significantly different to that for municipal wastewaters but again this will not affect the design of the lagoon system very much, because the design focuses on selecting the appropriate retention time and supplying the correct mass of oxygen per day rather than on the accuracy of the residual biodegradable wastewater organics concentration. For $R_{\mathrm{h}}>1.0-1.5 \mathrm{~d}$, it is easiest to assume that $\mathrm{BOD}_{5 \mathrm{fl}}=0$ and $\triangle \mathrm{BOD}_{5}=\mathrm{BOD}_{5 \mathrm{i}}$.

\section{The $2^{\text {nd }}$ lagoon}

The effluent from the $1^{\text {st }}$ lagoon, containing $\mathrm{BOD}_{5 \mathrm{fl}}$ and $X_{\mathrm{BH}}$, passes to the $2^{\text {nd }}$ lagoon with retention time $R_{\mathrm{h} 2}$. In this lagoon, utilization of the influent biodegradable organics will be complete $\left(\mathrm{BOD}_{5 \mathrm{f}_{2}}=0\right)$. Therefore, the unfiltered effluent $\mathrm{BOD}_{5}$ concentration, $\mathrm{BOD}_{52}$ from the $2^{\text {nd }}$ lagoon is:

BOD $_{52}=0.827 X_{B H 2} \mathrm{mg} / \mathrm{L}$

The filtered effluent $\mathrm{BOD}_{5}$ concentration is 0 , i.e.:

$\mathrm{BOD}_{5 f 2}=0 \mathrm{mg} / \mathrm{L}$

and the $\mathrm{OHO}$ concentration $\mathrm{X}_{\mathrm{BH} 2}$ is given by:

$X_{B H 2}=\frac{Y_{H} \gamma \text { BOD }_{5 f i}+X_{B H 1}}{\left(1+b_{H T} R_{h 2}\right)} \mathrm{mgVSS} / \mathrm{L}$

The carbonaceous oxygen demand in the $2^{\text {nd }}$ lagoon $\left(\mathrm{FO}_{\mathrm{c} 2}\right.$, $\mathrm{kgO} / \mathrm{d}$ ) is found from Eq. 39, i.e.:

$F O_{c 2}=\left(1-f_{c v} Y_{H}\right) Q_{i}\left(\gamma \mathrm{BOD}_{5 f 1}\right)+f_{c v}\left(1-f_{H}\right) b_{H T} M X_{B H 2} \mathrm{mgO} / \mathrm{d}$

where:

$M X_{B H 2}=$ OHO VSS mass in $2^{\text {nd }}$ lagoon:

$=V_{12} X_{B H 2} \quad \mathrm{kgVSS}$

$=R_{h 2} Q_{i} X_{B H 2} \mathrm{kgVSS}$

The VSS concentration cannot be calculated with the $\mathrm{BOD}_{5}$ as wastewater strength parameter. 


\section{The $3^{\text {rd lagoon }}$}

The effluent from the $2^{\text {nd }}$ lagoon, containing $X_{B{ }_{2} 2}$, passes to the $3^{\text {rd }}$ lagoon (if included) with retention time $R_{\mathrm{h} 3}$. In this lagoon, because utilization of wastewater biodegradable organics is complete, only endogenous respiration of the AS takes place (utilization of biodegradable organism organics). Therefore, the concentrations of the variables in the $3^{\text {rd }}$ lagoon, and its effluent, are:

$\mathrm{BOD}_{5 f 3}=0 \mathrm{mg} / \mathrm{L}$

$X_{B H 3}=\frac{X_{B H 2}}{\left(1+b_{H T} R_{h 3}\right)} \mathrm{mgVSS} / \mathrm{L}$

From Eq. 34 the unfiltered effluent $\mathrm{BOD}_{5}$ concentration from the $3^{\text {rd }}$ lagoon $\mathrm{BOD}_{53}$ is:

$\mathrm{BOD}_{53}=0.827 X_{B H 3} \mathrm{mgBOD}_{5} / \mathrm{L}$

The carbonaceous oxygen demand in the $3^{\text {rd }}$ lagoon $\left(F_{c 3}\right.$, $\mathrm{kgO} / \mathrm{d}$ ) is found from Eq. 39 with $\Delta \mathrm{BOD}_{5}=0$, i.e.

$F O_{c 3}=f_{c v}\left(1-f_{H}\right) b_{H T} M X_{B H 3} \mathrm{mgO} / \mathrm{d}$

where:

$$
\begin{aligned}
& M X_{B H 3}=\text { OHO VSS mass in } 3^{\text {rd }} \text { lagoon } \\
& \quad=V_{3} X_{B H 3} \mathrm{kgVSS} \\
& \quad=R_{h 3} Q_{\mathrm{i}} X_{B H 3} \mathrm{kgVSS}
\end{aligned}
$$

As for Lagoons 1 and 2, the VSS concentration in the $3^{\text {rd }}$ lagoon cannot be calculated with the $\mathrm{BOD}_{5}$ as wastewater strength parameter because the influent unbiodegradable particulate organics (UPO) concentration $\left(S_{u p i}, X_{I i}\right)$ is unknown.

\section{THE VALUE OF $\boldsymbol{Y}$}

From an examination of suspension mixed lagoon behaviour treating different industrial wastewaters reported in the literature, values of $\gamma$ were derived and are listed in Table 2.

\begin{tabular}{|l|c|l|c|}
\hline \multicolumn{4}{|c|}{ TABLE 2} \\
Wastewater of $\boldsymbol{\gamma}$ in Eq. & 33 for some industrial wastewaters \\
\hline Raw municipal & $\boldsymbol{\gamma}$ & Wastewater type & $\boldsymbol{\gamma}$ \\
\hline Oil refinery & 1.8 & Tomato juice & 1.8 \\
\hline Pulp and paper & 1.8 & Petrochemical & 1.8 \\
\hline Pea and strawberry & 1.8 & Textile & 1.8 \\
\hline Fruit cannery & 1.4 & Potato & 1.5 \\
\hline
\end{tabular}

With the $\gamma$ values in Table 2, and applying the above equations to assess lagoon performance as reported in the literature, the correlation between the calculated and observed unfiltered effluent $\mathrm{BOD}_{5}$ concentrations are shown in Fig. 2. In the assessment of each lagoon, the data were taken only where there was reasonable certainty that the system was suspension mixed. A difficulty in assessing the validity of the steady-state lagoon model is that rarely, if ever, are oxygen utilization rates reported for lagoons. Without this parameter, it is not possible to either (i) give very reliable values for $\gamma$ or (ii) validate the model better. Notwithstanding these difficulties, the correlation in Fig. 2 is reasonably good and so the steady-state lagoon model can be accepted as reasonably good.

\section{DESIGN OPTIMIZATION}

\section{The $1^{\text {st }}$ lagoon}

For design, valuable insights into the relative importance of different facets of the design, such as retention time, oxygen demand, and single versus series lagoons, can be gleaned from the $\mathrm{BOD}_{5}$-based steady-state lagoon model. For this discussion, complete utilization of influent wastewater organics in the $1^{\text {st }}$ lagoon will be accepted, i.e., $\triangle \mathrm{BOD}_{5}=\mathrm{BOD}_{5 \mathrm{i}}$. This considerably simplifies the model.

From Eq. 37, the $\mathrm{OHO}$ concentration in the $1^{\text {st }}$ lagoon $X_{B H i}$, is:

$X_{B H 1}=\frac{Y_{H} \gamma \text { BOD }_{5 i}}{\left(1+b_{H T} R_{h 1}\right)} \mathrm{mgVSS} / \mathrm{L}$

where:

$Y_{H} \gamma=$ yield coefficient in terms of $\mathrm{BOD}_{5}$

For most wastewaters, $\gamma=1.8$ and hence $Y_{H B}=\gamma Y_{H}=0.81$ $\mathrm{mgVSS} / \mathrm{mgBOD}_{5}$.

The unfiltered effluent $\mathrm{BOD}_{5}$ is given by Eq. 40 with $\mathrm{BOD}_{5 \mathrm{f} 1}=0$ and substituting Eq. 34 into this yields:

$\mathrm{BOD}_{51}=\frac{0.827 Y_{H} \gamma \mathrm{BOD}_{5 i}}{\left(1+b_{H T} R_{h 1}\right)} \mathrm{mgBOD}_{5} / \mathrm{L}$

and so

$\frac{\mathrm{BOD}_{51}}{\mathrm{BOD}_{5 i}}=\frac{0.67}{\left(1+b_{H T} R_{h 1}\right)} \mathrm{mgBOD}_{5} / \mathrm{L}$

The carbonaceous oxygen demand in the $1^{\text {st }}$ lagoon $\left(\mathrm{FO}_{\mathrm{cl}}\right.$, $\mathrm{kgO} / \mathrm{d}$ ) is found from Eq. 39, i.e.:

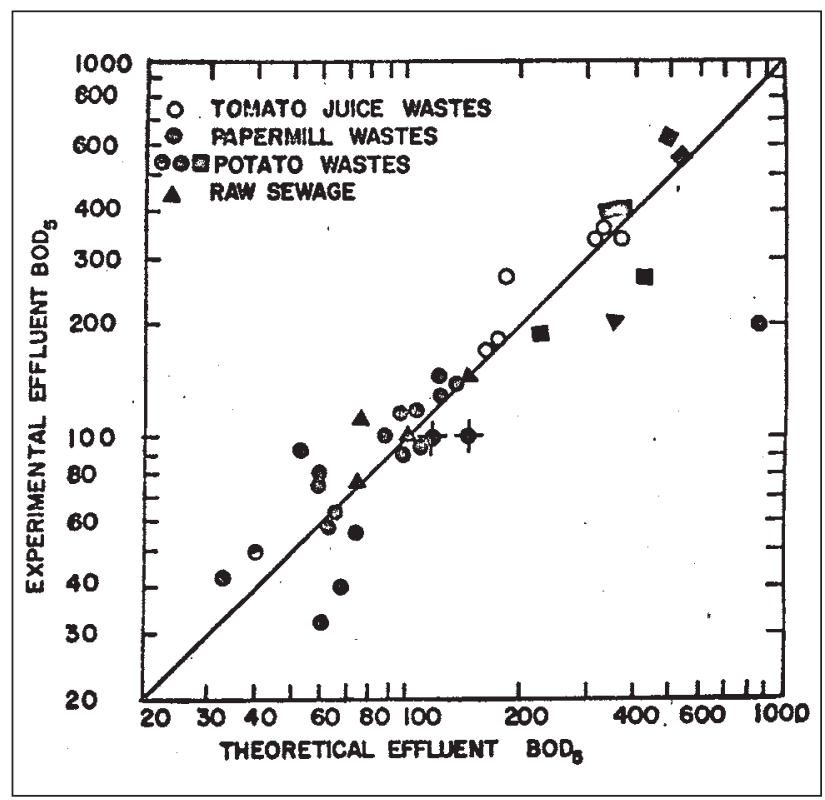

Figure 2

Correlation between theoretically calculated and experimentally observed BOD 5 concentrations of unfiltered effluents from suspension mixed aerated lagoons treating various wastewaters 
$\frac{F O_{c 1}}{Q_{i} \mathrm{BOD}_{5 i}}=\gamma\left(1-f_{c v} Y_{H}\right)+f_{c v}\left(1-f_{H}\right) b_{H T} \frac{Y_{H} \alpha R_{h 1}}{\left(1+b_{H T} R_{h 1}\right)}$

$\mathrm{kgO} / \mathrm{d}$ per $\mathrm{kgBOD}_{5} / \mathrm{d}$

Plots of Eqs 54 and 55 for a temperature of $20^{\circ} \mathrm{C}$, at which $b_{\mathrm{H} 20}$ $=0.24 / \mathrm{d}$, are given in Figs 3 and 4 , respectively. Figure 3 shows that an appreciable fraction of the $\mathrm{BOD}_{5}$ removal is due to growth (catabolism, Eq. A1) given by the difference $100-67$ $=33 \%$ at $R_{\mathrm{b}}=0$. The minimum retention time for a lagoon is about $1 \mathrm{~d}$, to ensure that the growth process on biodegradable wastewater organics is virtually complete, giving a $\mathrm{BOD}_{5}$ removal of $46 \%$ (Fig 4). At 2 d retention time, only an additional $8.7 \%$ $\mathrm{BOD}_{5}$ removal is obtained. As the retention time increases, the additional $\mathrm{BOD}_{5}$ removal added decreases with each day added. The same effect is observed in the oxygen demand (Fig. 4). Therefore, the volumetric efficiency of $\mathrm{BOD}_{5}$ removal decreases as the retention time increases. So as to make the most efficient use of the lagoon volume, the retention time needs to be as short as possible. However, at short retention times the $\mathrm{BOD}_{5}$ removal is unacceptably low. In-series suspension mixed lagoons have improved $\mathrm{BOD}_{5}$ removal compared with single lagoons at the same retention time, but not enough to make a significant difference. This is demonstrated below.

\section{The $2^{\text {nd }}$ lagoon}

From Eq. 46 with $\mathrm{BOD}_{5 \mathrm{fi}}=0$, the $\mathrm{OHO}$ concentration in the $2^{\text {nd }}$ lagoon and its effluent is:

$X_{B H 2}=\frac{X_{B H 1}}{\left(1+b_{H T} R_{h 2}\right)} \mathrm{mgVSS} / \mathrm{L}$

The unfiltered effluent $\mathrm{BOD}_{5}$ is given by Eq. 44 and successively substituting Eq. 56 for $X_{\mathrm{BH} 2}$ and Eq. 52 for $X_{\mathrm{BH} 1}$ into this yields:

$\mathrm{BOD}_{52}=0.827 X_{B H 2}=\frac{0.827 X_{B H 1}}{\left(1+b_{H T} R_{h 2}\right)}=\frac{0.827 Y_{H} \gamma \mathrm{BOD}_{5 i}}{\left(1+b_{H T} R_{h 2}\right)\left(1+b_{H T} R_{h 1}\right)}$

$\mathrm{mgBOD}_{5} / \mathrm{L}$

and so for $\gamma=1.8$ and $Y_{H}=0.45 \mathrm{mgVSS} / \mathrm{mgCOD}$ :

$\frac{\mathrm{BOD}_{5 e 1}}{\mathrm{BOD}_{5 i}}=\frac{0.67}{\left(1+b_{H T} R_{h 2}\right)\left(1+b_{H T} R_{h 1}\right)} \mathrm{mgBOD}_{5} / \mathrm{L}$

The carbonaceous oxygen demand in the $2^{\text {nd }}$ lagoon $\left(\mathrm{FO}_{\mathrm{c2}}\right.$, $\mathrm{kgO} / \mathrm{d}$ ) is found from Eq. 47, and successively substituting Eq. 56 for $X_{\mathrm{BH} 2}$ and Eq. 52 for $X_{\mathrm{BH} 1}$ into this yields:

$\frac{F O_{c 2}}{Q_{i} \mathrm{BOD}_{5 i}}=\frac{f_{c v}\left(1-f_{H}\right) b_{H T} Y_{H} \gamma R_{h 2}}{\left(1+b_{H T} R_{h 1}\right)\left(1+b_{H T} R_{h 2}\right)} \mathrm{kgO} / \mathrm{d}$ per $\mathrm{kgBOD}_{5} / \mathrm{d}$

If in Eq. $58, R_{\mathrm{h} 1}=R_{\mathrm{h} 2}$, then the ratio of the $\mathrm{BOD}_{5}$ reduction (due to endogenous respiration) from lagoon to lagoon down the series is the same. In Fig. 3, this is shown by the straight line from $67 \%$ at $R_{\mathrm{h}}=0$, through the $\mathrm{BOD}_{5}$ remaining at $R_{\mathrm{h} 1}=2 \mathrm{~d}$ (45.3\%) and continuing a further $2 \mathrm{~d}$ (for the $2^{\text {nd }}$ lagoon) to 4 d. Therefore, in double lagoon system with $4 \mathrm{~d}$ retention time, the $\mathrm{BOD}_{5}$ remaining is $30.8 \%$ whereas in a single lagoon of $4 \mathrm{~d}$ retention time, the $\mathrm{BOD}_{5}$ remaining is $34.2 \%$. This difference is very small, too small to make much difference between single and in-series lagoons. The oxygen demand reflects the same outcome. From Eqs 55 and 58, the ratio of the oxygen demand in the $1^{\text {st }}$ and $2^{\text {nd }}$ lagoon is $0.21 / 0.91=0.23$, making the oxygen demand in the $2^{\text {nd }}$ lagoon only $23 \%$ of that in the $1^{\text {st }}$ lagoon (see Fig. 4 for an approximate visual difference). Because OD is a direct measure of the BOD removal, it is clear that the removal in the $2^{\text {nd }}$ lagoon, of equal volume to the $1^{\text {st }}$, is only $23 \%$ of that in the $1^{\text {st }}$. With such a low OD, the aeration power input is insufficient to establish suspension mixing in the second lagoon. The design approach is therefore to meet the OD required in the $2^{\text {nd }}$ lagoon but not to supplement the aeration power input with mixing energy to establish suspension mixing, but instead to allow the $2^{\text {nd }}$ lagoon to be facultative. By being facultative, the $2^{\text {nd }}$ lagoon achieves far greater $\mathrm{BOD}_{5}$ removals by sedimentation to a sludge layer and oxidation by anaerobic fermentation than by aerobic oxidation. (With aerobic digestion, multiple reactor digesters do achieve significantly lower effluent active fractions (equivalent to $\mathrm{BOD}_{5}$ remaining) than the single reactor digester at the same retention time (Ekama et al., 2006). Even though one expects the same outcome for suspension mixed aerated lagoons because the biological process is the same, i.e. endogenous respiration, the reason that it doesn't yield the same outcome is because the retention times in the aerated lagoons are an order of magnitude shorter than in aerobic digesters.)

In order to demonstrate that the input by the aeration system establishes suspension mixing and facultative conditions in the $1^{\text {st }}$ and $2^{\text {nd }}$ lagoons, respectively, the power requirements for aeration need to be determined. This is presented below.

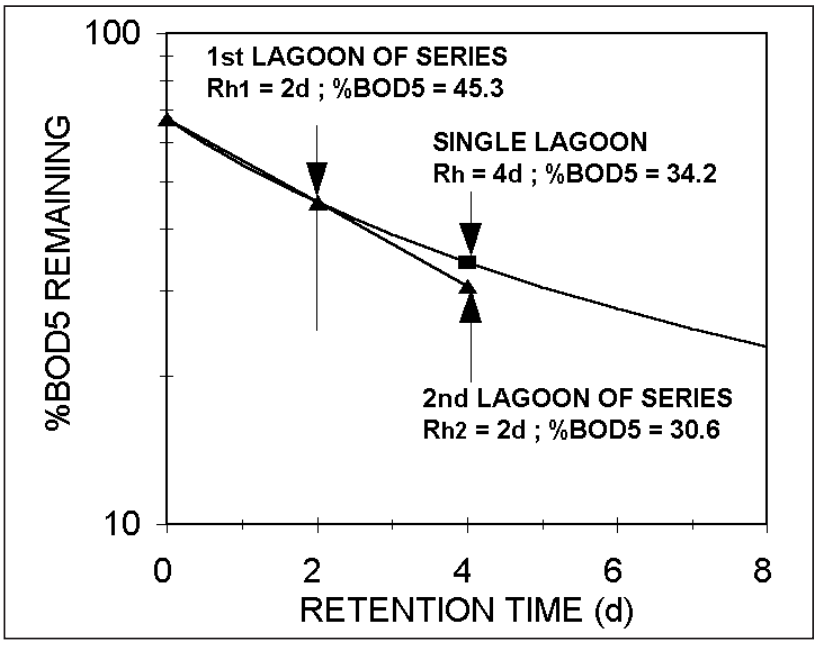

Figure 3

Percentage $\mathrm{BOD}_{5}$ remaining versus retention time is single and double suspension mixed lagoon at $20^{\circ} \mathrm{C}$

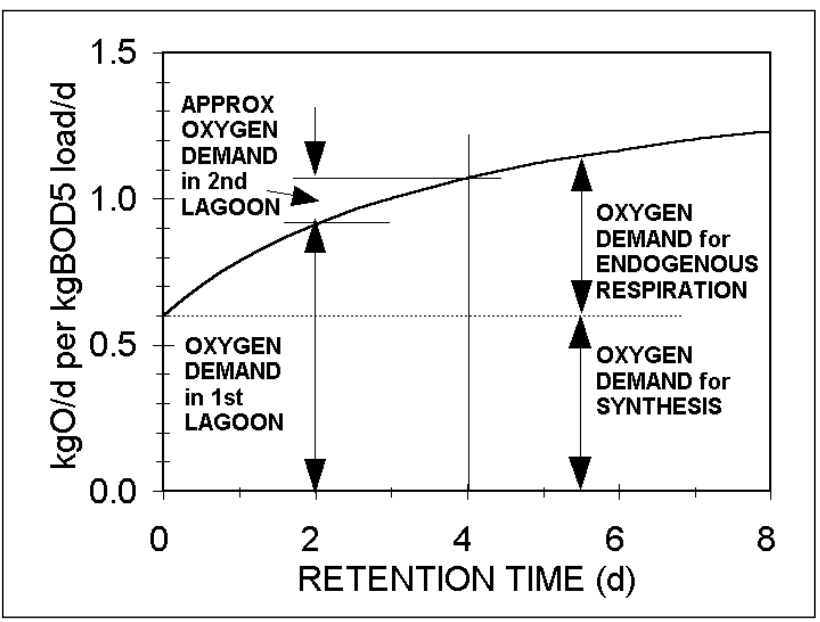

Figure 4

Carbonaceous oxygen demand versus retention time in single suspension mixed lagoon at $20^{\circ} \mathrm{C}$ 


\section{POWER REQUIREMENTS FOR AERATION}

The oxygen transfer rate (OTR) of an aeration device is given by its mass oxygen transfer per unit energy consumption $\mathrm{kgO} / \mathrm{kWh}$ - under standard conditions, which are into clean de-oxygenated tap water at STP - standard temperature $\left(20^{\circ} \mathrm{C}\right)$ and pressure $(1 \mathrm{~atm}=760 \mathrm{~mm} \mathrm{Hg})$. This OTR value $\left(R_{\mathrm{std}}\right)$ is a characteristic of the aeration device and is specified by the manufacturers. The OTR under standard conditions $\left(R_{s t d}\right)$ needs to be corrected for the site conditions $\left(R_{\text {act }}\right)$ where the aeration device is installed. The parameters that are different at the site compared to standard conditions are (i) atmospheric pressure and water temperature, (ii) the oxygen mass transfer coefficient $K_{L a}$ and (iii) non-zero water dissolved oxygen (DO) concentration. The saturated DO concentration under STP is corrected for temperature and atmospheric pressure at the site and for impurities in the wastewater $(\beta)$. The $K_{L a}$ coefficient is corrected for temperature $(\theta)$ and impurities in the wastewater $(\alpha)$. Details of these corrections are given in WPCF/ ASCE (1988).

Combining all the corrections gives the ratio of the OTR under site and standard conditions, i.e.:

$\frac{R_{a c t}}{R_{\text {std }}}=\frac{\alpha \theta^{(T-20)}}{C_{S s t d}}\left(\frac{51.6}{51.6+T} \frac{P_{a c t}-p_{a c t}}{P_{s t d}-p_{s t d}} \beta C_{S s t d}-C_{L}\right)$

where:

$\alpha=K_{L a}$ correction factor of impurities

$\theta=K_{L a}$ correction factor of temperature

$=1.012$ for mechanical surface aerators

$C_{\text {std }}=$ saturation $\mathrm{DO}$ concentration under standard conditions = $9.07 \mathrm{mgO} / \mathrm{L}$ at STP

$T=$ temperature at the site $\left({ }^{\circ} \mathrm{C}\right)$

$P_{\text {act }}=$ barometric pressure at site $(\mathrm{mmHg})$

$P_{\text {std }}=$ standard barometric pressure $(\mathrm{mmHg})=760 \mathrm{mmHg}$

$p_{a c t}=$ water vapour pressure at site $(\mathrm{mmHg})$

$p_{\text {std }}=$ water vapour pressure at standard temperature $20^{\circ} \mathrm{C}$

$(\mathrm{mmHg})=17.51 \mathrm{mmHg}$

$\beta=C_{S s t d}$ correction factor of impurities

$C_{L}=\mathrm{DO}$ concentration in lagoon $(\mathrm{mgO} / \mathrm{L})$.

The effect of temperature and altitude on the $\mathrm{R}_{a c t} / \mathrm{R}_{\text {std }}$ ratio is shown graphically in Fig. 5 . The relationship between altitude and barometric pressure in $\mathrm{mmHg}$ can be approximated with

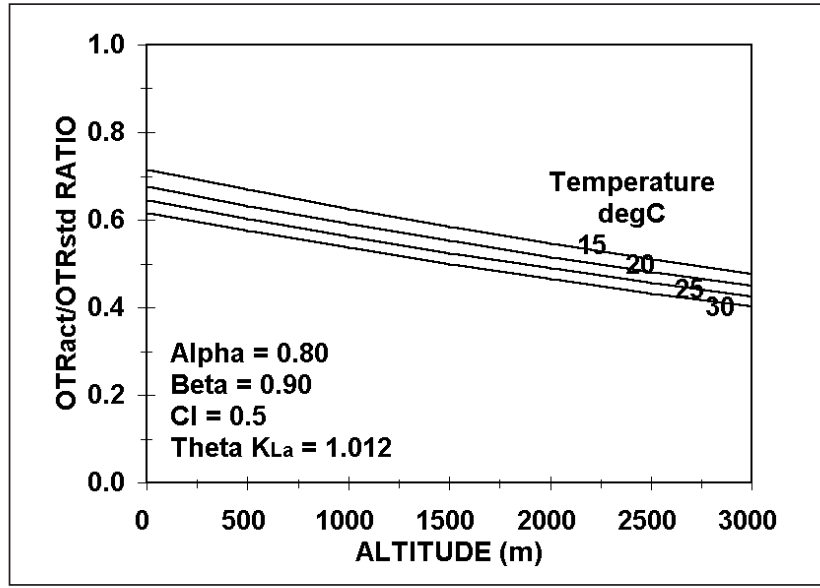

Figure 5

Actual/standard oxygen transfer rate (OTR) ratio versus altitude at different temperatures
$P_{\text {act }}=10^{2.8117-0.000053 \mathrm{Alt}} \mathrm{mmHg}\left(R^{2}=0.9999\right)$

where $A l t=$ altitude in $\mathrm{m}$, and the relationship between the saturated vapour pressure of water and temperature between 5 and $35^{\circ} \mathrm{C}$ can be approximated with:

$p_{\text {act }}=p_{20} 1.0639^{(T-20)} \mathrm{mmHg}\left(R^{2}=0.9999\right)$

where:

$p_{20}=$ saturated vapour pressure of water at $20^{\circ} \mathrm{C}$

$=17.51 \mathrm{mmHg}$

From Fig. 5, it can be seen that the effect of temperature and altitude is not very strong on the $R_{\text {act }} / R_{\text {std }}$ ratio, only $25 \%$ between 15 and $30^{\circ} \mathrm{C}$ and 0 and $3000 \mathrm{~m}$ and decreasing as both temperature and altitude increase. The lowest power requirement for aeration for a particular carbonaceous oxygen demand (OD) therefore will be at sea level and low temperature. As temperature and altitude increase, the power input for a fixed OD increases and therefore increases the power density $\left(\mathrm{W} / \mathrm{m}^{3}\right)$ for mixing in the lagoon.

In Eq. 59, the $1^{\text {st }}$ and $2^{\text {nd }}$ terms in front of the $\beta$ are the saturation $\mathrm{DO}$ concentration correction for temperature and pressure, respectively. Accepting an altitude of $1000 \mathrm{~m}$, which gives a site barometric pressure of about $673 \mathrm{mmHg}$, maximum and minimum seasonal temperatures of 14 and $22^{\circ} \mathrm{C}$, a manufacturer's $R_{\text {std }}$ of $2.5 \mathrm{kgO} / \mathrm{kWh}$ and a lagoon design DO concentration of $0.5 \mathrm{mgO} / \mathrm{L}$, and $\alpha=0.80$ and $\beta=0.90$ gives the $R_{\text {act }}$ values for mechanical surface aerators listed in Table 3 .

TABLE 3

Calculation of actual oxygen transfer rate (OTR) under site conditions from the manufacturer's standard OTR

\begin{tabular}{|l|c|c|c|c|}
\hline \multirow{2}{*}{ Parameter } & \multirow{2}{*}{ Units } & \multirow{2}{*}{ Std } & \multicolumn{2}{|c|}{ Site } \\
\cline { 4 - 5 } & & & $\mathbf{1 4}^{\circ} \mathbf{C}$ & $\mathbf{2 2}^{\circ} \mathbf{C}$ \\
\hline Altitude & $\mathrm{m}$ & 0 & 1000 & 1000 \\
\hline Atmos. pressure & $\mathrm{mmHg}$ & 760 & 673 & 673 \\
\hline Temperature & ${ }^{\circ} \mathrm{C}$ & 20 & 14 & 22 \\
\hline Vapour pressure & $\mathrm{mmHg}$ & 17.5 & 12.07 & 19.82 \\
\hline DO temp correction & - & 1 & 1.132 & 0.963 \\
\hline DO pres correction & - & 1 & 0.89 & 0.88 \\
\hline DO saturation & $\mathrm{mg} \mathrm{O/L}$ & 9.07 & 8.23 & 6.92 \\
\hline$K_{\text {La }}$ correction & - & - & 0.931 & 1.024 \\
\hline OTR - kgO/kWh & & 2.5 & 1.586 & 1.449 \\
\hline
\end{tabular}

Once the actual OTR at the site is known, the power requirements for aeration are calculated from the mass oxygen demand (OD) per day (flux) $\mathrm{FO}_{c}$, i.e.:

$P_{n}=\frac{F O_{c n}}{24 R_{a c t}} \mathrm{~kW}$

and the power density by:

$P_{d n}=\frac{P_{n}}{V_{n}}=\frac{F O_{c n}}{24 R_{a c t} R_{h n} Q_{i}}=\frac{1000 O_{c n}}{24 R_{a c t}} \mathrm{~W} / \mathrm{m}^{3}$

where:

$\mathrm{O}_{\mathrm{cn}}=$ oxygen demand $(\mathrm{OD})$ in $\mathrm{kgO} /\left(\mathrm{m}^{3} \cdot \mathrm{d}\right)$ in $n^{\text {th }}$ lagoon $=F O_{c} / V$

with $F O_{\text {cn }}$ in $\mathrm{kgO} / \mathrm{d}$ and lagoon volume $V_{\mathrm{n}}$ in $\mathrm{m}^{3}$ 


\section{MIXING POWER REQUIREMENTS}

The power density expressed in $\mathrm{W} / \mathrm{m}^{3}$ is the usual way in which mixing power density in biological reactors is defined. However, this parameter only partially defines the mixing conditions. Other parameters such as surface aerator and mixer design, spacing of aerators, aerator rotational speed and reactor geometry all influence the mixing efficiency at a particular power density. However, the effect of these factors is difficult and complex to define and adds unnecessary detail when the power densities for suspension or facultative mixing regimes are not well known.

Very little information is available on the power density required to maintain suspension mixing. According to Von der Emde (1969), Kalbskopf proposed the power densities in Table 4 to maintain AS in suspension.

\begin{tabular}{|l|l|l|l|}
\hline \multicolumn{4}{|c|}{$\begin{array}{c}\text { TABLE } 4 \\
\text { Power densities for suspension mixing in AS biological } \\
\text { reactors }\end{array}$} \\
\hline Reactor volume $\left(\mathrm{V}, \mathrm{m}^{3}\right)$ & 500 & 1000 & 2000 \\
\hline Power density $\left(P_{\mathrm{d}}, \mathrm{W} / \mathrm{m}^{3}\right) \mathrm{w}$ & 20 & 15 & 10 \\
\hline
\end{tabular}

The power density $\left(P_{\mathrm{d}}\right)$ in Fig. 6 can be related to the volume with the following approximate equation:

$P_{d}=\frac{450}{\sqrt{V}} \mathrm{~W} / \mathrm{m}^{3}$

A plot of Eq. 64 is shown in Fig. 6 (solid line). Also shown are the power densities $(\bullet)$ in aerated lagoons which, apparently, behaved kinetically in accordance with the theory for suspension mixed aerated lagoons (data on mixing energies from Beychok, 1971). Although this does not constitute a satisfactory proof that the lagoons were indeed suspension mixed, it does support the implications of Eq. 64 that the power density decreases as volume increases. Only one instance was found which could be used to validate Eq. 64; Balasha and Sperber (1975) operated an aerated lagoon of $14000 \mathrm{~m}^{3}$ at a power density of $2.7 \mathrm{~W} / \mathrm{m}^{3}$ and reported no evident sludge deposition $(\bigotimes)$. For this volume, the power density from Eq. 64 is $3.8 \mathrm{~W} / \mathrm{m}^{3}$. Therefore, a somewhat lower power density than estimated by Eq. 64 establishes suspension

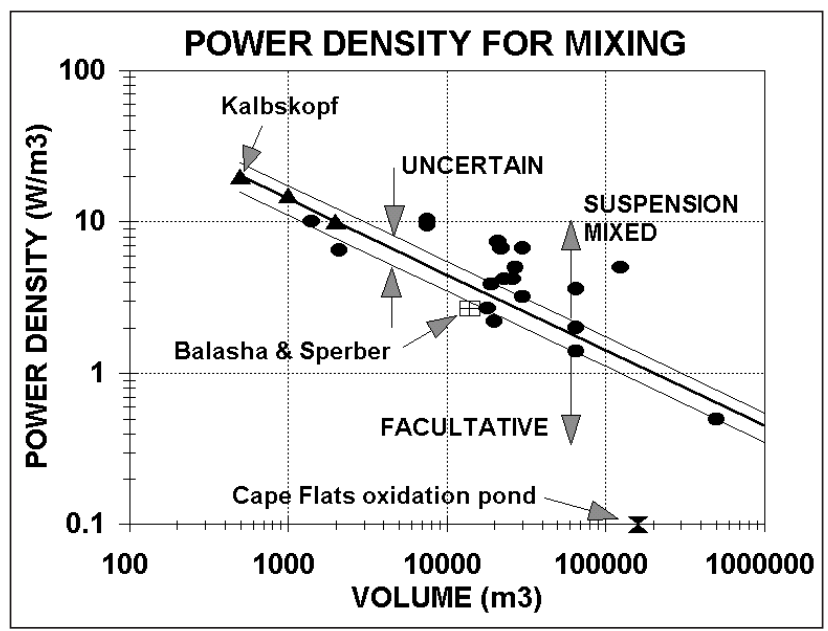

Figure 6

Power density (in $\mathrm{W} / \mathrm{m}^{3}$ ) versus volume (in $\mathrm{m}^{3}$ ) for estimation of mixing regime (450/ $\mathrm{N}^{-0.5}$, Eq. 64) - suspension mixed above line 500 $\mathrm{N}^{-0.5}$ and facultative below line $400 \mathrm{~N}$.0.5, between lines mixing regime uncertain mixing. Since the objective of Eq. 64 is to establish a minimum lower value in the $1^{\text {st }}$ lagoon, to ensure suspension mixing, and an upper maximum value for the $2^{\text {nd }}$ lagoon, to ensure facultative conditions, overestimation by Eq. 64 for suspension mixing conditions is acceptable. Therefore, even though application of Eq. 64 to aerated lagoons extrapolates it way out of the range of AS biological reactor volumes in Table 4, it would appear that Eq. 64 can be applied (with caution) to determine the mixing regime from the power density in large aerated lagoons - provided the actual power density in the $1^{\text {st }}$ and $2^{\text {nd }}$ lagoons are significantly above and below that given by Eq. 64, suspension and facultative mixing regimes are likely to be present in the $1^{\text {st }}$ and $2^{\text {nd }}$ lagoons, respectively.

Knowledge of the minimum power densities for suspension mixed and facultative mixing regimes is of crucial importance in the design of series lagoon systems. In the $1^{\text {st }}$ lagoon, suspension mixing is essential for rapid transformation into settleable solids by (i) growth of OHO VSS from the influent biodegradable soluble organics and (ii) growth and flocculation of the influent particulate biodegradable and unbiodegradable organics, and in the $2^{\text {nd }}$ lagoon, facultative conditions are essential to settle out the settleable solids formed in the $1^{\text {st }}$ lagoon to produce an effluent low in suspended solids. Interestingly, because the oxygen demand in the $1^{\text {st }}$ lagoon includes the growth oxygen demand, its aeration power input invariably is sufficient for suspension mixing, and because the oxygen demand in the $2^{\text {nd }}$ lagoon excludes the growth oxygen demand, its aeration power input invariably is insufficient for suspension mixing. This will be demonstrated in a worked example below.

Knowledge of the minimum power density for suspension mixing in different volumes also allows intelligent application by scaling up pilot plant data to full-scale plant design. A pilot plant may have been deliberately operated as a facultative lagoon with a certain power density. If the full-scale plant is designed with the same power density, the lagoon may be suspension mixed and deliver an effluent $\mathrm{BOD}_{5}(\mathrm{COD})$ very different from that expected from the pilot plant performance.

\section{DESIGN EXAMPLE}

To demonstrate the aerated lagoon design procedure based on the steady-state AS model, the example raw wastewater in WRC (1984), i.e. $15 \mathrm{ML} / \mathrm{d}$ at $750 \mathrm{mgCOD} / \mathrm{L}$, is treated in a two-inseries aerated lagoon system, the $1^{\text {st }}$ suspension mixed and the $2^{\text {nd }}$ facultative. The hydraulic retention time (HRT) in the $1^{\text {st }}$ lagoon is selected at $1.5 \mathrm{~d}$ to ensure near complete utilization of influent biodegradable organics at the minimum temperature of $14^{\circ} \mathrm{C}$. The $2^{\text {nd }}$ lagoon is designed for a retention time of 4 $\mathrm{d}$. Because the oxygen demand is highest at the maximum temperature, the calculations are repeated at $22^{\circ} \mathrm{C}$ to determine the aeration power requirements, which establishes the mixing conditions in the lagoons. Complete utilization of biodegradable organics in the $1^{\text {st }}$ lagoon is assumed because HRT selection is based on this (Fig 1). The results of the calculations for the COD and $\mathrm{BOD}_{5}$ models are given in Table 5 . The oxygen transfer rate (OTR) at the site were calculated from the information in Table 3.

From Table 5, the following can be noted:

(1) The COD- and $\mathrm{BOD}_{5}$-based models give identical results. This is because the same $\gamma$ value of 1.8 was used (i) to calculate the influent $\mathrm{BOD}_{5}$ concentration, which is 325 $\mathrm{mgO} / \mathrm{L}$ and (ii) in the $\mathrm{BOD}_{5}$ model calculations. From Eq. A10, which is based on the AS growth-endogenous 
respiration model, the $\gamma$ value is 1.41 yielding an influent $\mathrm{BOD}_{5}$ concentration of $415 \mathrm{mgO} / \mathrm{L}$. Differences in $\gamma$ values do not affect the $\mathrm{BOD}_{5}$-based model, provided the same value is used to calculate the influent $\mathrm{BOD}_{5}$ and in the model. If only the influent $\mathrm{BOD}_{5}$ concentration is known, then it is best to select a $\gamma$ value on the high end, because this leads a more conservative design, i.e., higher oxygen demand.

(2) The effluent COD and $\mathrm{BOD}_{5}$ concentrations from the $2^{\text {nd }}$ lagoon are uncertain. The concentrations given in Table 5 are the lowest and highest possible values. If 100\% solids removal is achieved in the $2^{\text {nd }}$ lagoon, which is unlikely, the unfiltered effluent COD concentration is the unbiodegradable soluble concentration, i.e., $53 \mathrm{mgCOD} / \mathrm{L}$ and the $\mathrm{BOD}_{5}$ is 0 . At the other extreme, if the $2^{\text {nd }}$ lagoon were suspension mixed, the unfiltered effluent COD concentration is the soluble unbiodegradable COD plus the COD of the AS solids, i.e., 354 and $375 \mathrm{mgCOD} / \mathrm{L}$ at 22 and $14^{\circ} \mathrm{C}$, respectively; the effluent $\mathrm{BOD}_{5}$ is 79 and 93 $\mathrm{mgO} / \mathrm{L}$ at 22 and $14^{\circ} \mathrm{C}$ respectively. From this it can be seen that if settlement of solids in the $2^{\text {nd }}$ lagoon is good, the lagoon system can achieve very respectable effluent organic concentrations. The disadvantage of lagoons is not their organic removal efficiency, which clearly can be good, but that lagoon systems, due to their low retention times, rarely nitrify. For municipal wastewater with high influent TKN concentrations this is a severe shortcoming. For agroindustrial wastewaters with much lower TKN/COD ratios, the lack of nitrification is not such a serious shortcoming. Indeed, with some agro-industrial wastewaters $\mathrm{N}$ and $\mathrm{P}$ may have to be dosed to ensure optimal $\mathrm{OHO}$ growth. The $\mathrm{N}$ and $\mathrm{P}$ dosages can be calculated with the AS model equations (Marais and Ekama, 1976; WRC, 1984; Henze et al., 2008).

(3) The power density $\left(P_{\mathrm{d}}\right)$ supplied by the aeration system in the $1^{\text {st }}$ lagoon is $5.38 \mathrm{~W} / \mathrm{m}^{3}$ at $22^{\circ} \mathrm{C}$. As a $P_{\mathrm{d}}>3 \mathrm{~W} / \mathrm{m}^{3}$ is required for suspension mixing, the $1^{\text {st }}$ lagoon will be suspension mixed. The power density of the aeration system in the $2^{\text {nd }}$ lagoon is only $0.82 \mathrm{~W} / \mathrm{m}^{3}$ and, as $1.84 \mathrm{~W} / \mathrm{m}^{3}$ are required for suspension mixing, the lagoon will be facultative. Because the retention time of the $1^{\text {st }}$ lagoon is generally short (1-2 d) and oxygen demand includes that for growth, it will generally be found that the $1^{\text {st }}$ lagoon will be suspension mixed, unless the influent COD concentration is low. Furthermore, because the retention time of the $2^{\text {nd }}$ lagoon usually is longer than the $1^{\text {st }}(3-6 \mathrm{~d})$, and oxygen demand is that for endogenous respiration only, it will be found that the $2^{\text {nd }}$ lagoon is generally facultative, unless the influent COD is high.

Elaborating on (3) by making the influent flow and COD concentration variables, the power densities for aeration and mixing for the $1^{\text {st }}$ and $2^{\text {nd }}$ lagoons are given by:

$P_{d 1}=\frac{S_{t i}\left(1-f_{S^{\prime} u p}-f_{S^{\prime} u s}\right)}{24 R_{a c t}}\left[\frac{\left(1-f_{c v} Y_{H}\right)}{R_{h 1}}+\frac{f_{c v}\left(1-f_{H}\right) b_{H T} Y_{H}}{\left(1+b_{H T} R_{h 1}\right)}\right]$

$>\frac{450}{\left(1000 R_{h 1} Q_{i}\right)^{0.5}} \mathrm{~W} / \mathrm{m}^{3}$

$P_{d 2}=\frac{f_{c v}\left(1-f_{H}\right) b_{H T} Y_{H} S_{t i}\left(1-f_{S^{\prime} u p}-f_{S^{\prime} u s}\right)}{24 R_{a c t}\left(1+b_{H T} R_{h 1}\right)\left(1+b_{H T} R_{h 2}\right)}<\frac{450}{\left(1000 R_{h 2} Q_{i}\right)^{0.5}} \mathrm{~W} / \mathrm{m}^{3}$

where the LHS of Eqs 65 and 66 are the power densities due to aeration in the $1^{\text {st }}\left(P_{\mathrm{d} 1}\right)$ and $2^{\text {nd }}\left(P_{\mathrm{d} 2}\right)$ lagoons and the RHS the power density limit between suspension mixing $(>)$ and
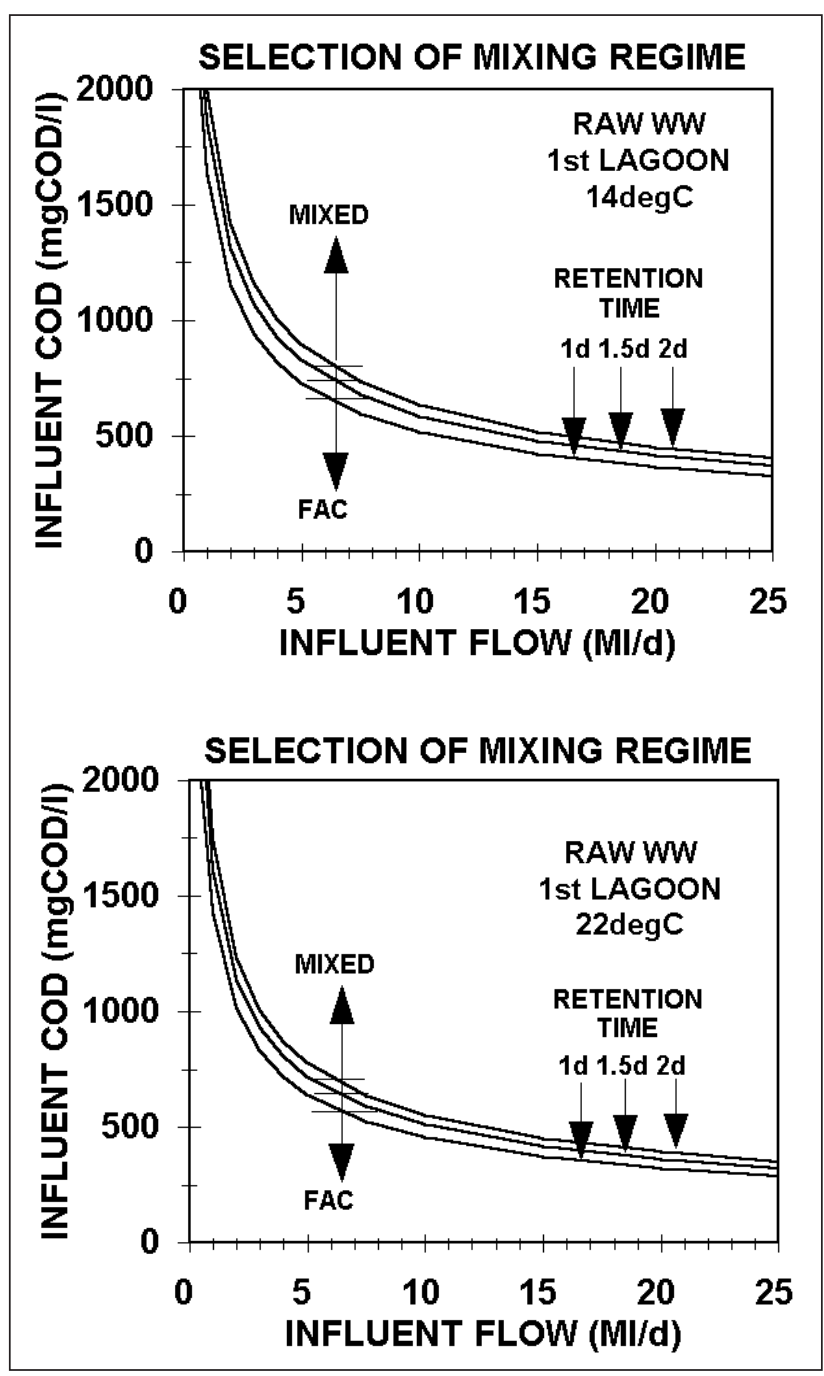

Figure 7

Municipal raw WW influent COD concentration versus influent flow for suspension mixing in the $1^{\text {st }}$ lagoon at retention times of 1.0, 1.5 d and 2.0 $d$ and 1000 m altitude at $14^{\circ} \mathrm{C}$ (Fig. 7a) and $22^{\circ} \mathrm{C}$ (Fig. 7b).

facultative $(<)$ conditions in the lagoons. Note that in Eqs 65 and $66 \mathrm{Q}_{\mathrm{i}}$ is in $\mathrm{ML} / \mathrm{d}$.

From Eq. 65, Figs 7a and $b$ show the minimum raw wastewater, with unbiodegradable soluble organics (USO) COD fraction $\left(f_{S_{\text {us }}}\right)=0.07$ and unbiodegradable particulate organics (UPO) COD fraction $f_{\text {Sup }}=0.15$ ), influent COD concentration versus the influent flow to achieve suspension mixing in the $1^{\text {st }}$ lagoon at retention times of 1.0, 1.5, and $2.0 \mathrm{~d}$ for 14 (Fig. 7a) and $22^{\circ} \mathrm{C}$ (Fig. $7 \mathrm{~b}$ ) based on the aeration system characteristics in Table 3. While the positions of the lines change only marginally for different wastewater and aeration system characteristics, the lines in Figs $7 \mathrm{a}$ and $\mathrm{b}$ show a general trend, i.e.:

- For a fixed influent flow, the shorter the HRT of the $1^{\text {st }}$ lagoon $\left(R_{\mathrm{h} 1}\right)$, the lower the influent COD concentration $\left(S_{\mathrm{ti}}\right)$ to achieve suspension mixing in the $1^{\text {st }}$ lagoon.

- At the same HRT, the lower the wastewater temperature, the higher the influent COD concentration for suspension mixing in the $1^{\text {st }}$ lagoon.

- The higher the influent flow, the larger the lagoon volume at a particular HRT, the lower the power density required for 


\begin{tabular}{|c|c|c|c|c|c|c|c|c|c|c|c|}
\hline \multicolumn{12}{|c|}{$\begin{array}{l}\text { TABLE } 5 \\
\text { Design example calculation results from the COD- and } B O D_{5} \text {-based steady-state aerated lagoon design equations for a two-in-series } \\
\text { lagoon system treating the example raw wastewater at } 14 \text { and } 22^{\circ} \mathrm{C} \text {. For the } \mathrm{BOD}_{5} \text {-based equations, the } \gamma \text { value selected for the raw } \\
\text { wastewater is } 1.8 \text {, giving an influent } \mathrm{BOD}_{5} \text { of } 325 \mathrm{mg} / \mathrm{L} \text {. }\end{array}$} \\
\hline Parameter & Units & Eq. No & Summer & & Winter & & Eq. No & Summer & & Winter & \\
\hline & & & $1^{\text {st }} \operatorname{Lag}$ & $2^{\text {nd }} \operatorname{Lag}$ & $2^{\text {nd }} \operatorname{Lag}$ & $2^{\text {nd }} \operatorname{Lag}$ & & $1^{\text {st }} \operatorname{Lag}$ & $2^{\text {nd }} \operatorname{Lag}$ & $1^{\text {st }} \operatorname{Lag}$ & $2^{\text {nd }} \operatorname{Lag}$ \\
\hline Temp & ${ }^{\circ} \mathrm{C}$ & & 22 & 22 & 14 & 14 & & 22 & 22 & 14 & 14 \\
\hline$b_{\mathrm{HT}}$ rate & $/ \mathrm{d}$ & 4.20 & 0.254 & 0.254 & 0.202 & 0.202 & 4.20 & 0.254 & 0.254 & 0.202 & 0.202 \\
\hline$K_{\mathrm{vT}}$ rate & $\mathrm{L} /(\mathrm{mgVSS} \cdot \mathrm{d})$ & 13 & \multicolumn{4}{|c|}{$\begin{array}{l}100 \% \text { WW Bio COD utilization - not } \\
\text { required }\end{array}$} & 13 & \multicolumn{4}{|c|}{ 100\% WW BOD utilization - not required } \\
\hline Ret Time & $\mathrm{D}$ & & 1.5 & 4 & 1.5 & 4 & & 1.5 & 4 & 1.5 & 4 \\
\hline Volume & ML & 12 & 22.5 & 60.0 & 22.5 & 60.0 & 12 & 22.5 & 60.0 & 22.5 & 60.0 \\
\hline$S_{\text {bn }}$ & $\mathrm{mgCOD} / \mathrm{L}$ & - & 0.0 & 0.0 & 0.0 & 0.0 & $35 / 45$ & 0.0 & 0.0 & 0.0 & 0.0 \\
\hline$S_{\text {tfn }}$ & $\mathrm{mgCOD} / \mathrm{L}$ & $10 / 21$ & 53 & 53 & 53 & 53 & $35 / 45$ & & & & \\
\hline$X_{\mathrm{BHn}}$ & mgVSS/L & $6 / 17$ & 191 & 95 & 202 & 112 & $37 / 46$ & 191 & 95 & 202 & 112 \\
\hline$X_{\text {En }}$ & $\mathrm{mgVSS} / \mathrm{L}$ & $7 / 18$ & 15 & 34 & 12 & 30 & - & 15 & 34 & 12 & 30 \\
\hline$X_{\text {In }}$ & $\mathrm{mgVSS} / \mathrm{L}$ & $4 / 15$ & 76 & 76 & 76 & 76 & - & & & & \\
\hline$X_{\mathrm{vn}}$ & $\mathrm{mgVSS} / \mathrm{L}$ & $8 / 19$ & 281 & 204 & 290 & 218 & - & & & & \\
\hline$S_{\mathrm{tn}}$ & $\mathrm{mgCOD} / \mathrm{L}$ & $9 / 20$ & 469 & $53 ?$ & 482 & $53 ?$ & $40 / 44$ & 158 & $0 ?(79)$ & 167 & $0 ?(93)$ \\
\hline$F O_{\mathrm{sn}}$ & $\mathrm{kgO} / \mathrm{d}$ & - & 2931 & 0 & 2931 & 0 & - & 2931 & 0 & 2931 & 0 \\
\hline$F O_{\text {en }}$ & $\mathrm{kgO} / \mathrm{d}$ & - & 1290 & 1706 & 1088 & 1604 & - & 1290 & 1706 & 1088 & 1604 \\
\hline$F O_{c n}$ & $\mathrm{kgO} / \mathrm{d}$ & $11 / 22$ & 4221 & 1706 & 4019 & 1604 & $39 / 47$ & 4221 & 1706 & 4019 & 1604 \\
\hline OUR & $\mathrm{mgO} /(\mathrm{L} \cdot \mathrm{h})$ & - & 7.8 & 1.2 & 7.4 & 1.1 & - & 7.8 & 1.2 & 7.4 & 1.1 \\
\hline \multirow[t]{3}{*}{ COD Bal } & In $\mathrm{kgO} / \mathrm{d}$ & - & 11250 & 7029 & 11250 & 7231 & - & & & & \\
\hline & Out $\mathrm{kgO} / \mathrm{d}$ & - & 11250 & 7029 & 11250 & 7231 & - & & & & \\
\hline & COD Bal \% & - & 100.0 & 100.0 & 100.0 & 100.0 & - & & & & \\
\hline$p_{\text {act }}$ & $\mathrm{mmHg}$ & 61 & 19.82 & 19.82 & 12.07 & 12.07 & 61 & 19.82 & 19.82 & 12.07 & 12.07 \\
\hline$C_{\mathrm{s}}$ & $\mathrm{mgO} / \mathrm{L}$ & - & 7.30 & 7.30 & 8.68 & 8.68 & - & 7.30 & 7.30 & 8.68 & 8.68 \\
\hline$R_{\text {act }}$ & $\mathrm{kgO} / \mathrm{kWh}$ & 59 & 1.453 & 1.453 & 1.591 & 1.591 & 59 & 1.453 & 1.453 & 1.591 & 1.591 \\
\hline Power & $\mathrm{kW}$ & 60 & 121.0 & 48.9 & 105.3 & 42.0 & 60 & 121.0 & 48.9 & 105.3 & 42.0 \\
\hline$P$ density & $\mathrm{W} / \mathrm{m}^{3}$ & 61 & 5.38 & 0.82 & 4.68 & 0.70 & 61 & 5.38 & 0.82 & 4.68 & 0.70 \\
\hline$P$ for mix & $\mathrm{W} / \mathrm{m}^{3}$ & 64 & 3.00 & 1.84 & 3.00 & 1.84 & 64 & 3.00 & 1.84 & 3.00 & 1.84 \\
\hline Type & & & Susp & $\mathrm{Fac}$ & Susp & $\mathrm{Fac}$ & & Susp & $\mathrm{Fac}$ & Susp & Fac \\
\hline
\end{tabular}


suspension mixing, and hence the lower the influent COD concentration $\left(S_{\mathrm{ti}}\right)$.

Because the minimum HRT for the $1^{\text {st }}$ lagoon is around 1 $\mathrm{d}$ at $22^{\circ} \mathrm{C}$ and $1.5 \mathrm{~d}$ at $14^{\circ} \mathrm{C}$, the minimum influent COD concentration to establish suspension mixing is about 650 and $830 \mathrm{mgCOD} / \mathrm{L}$ at 22 and $14^{\circ} \mathrm{C}$ for an influent flow of $5 \mathrm{ML} / \mathrm{d}$. At $0.5 \mathrm{ML} / \mathrm{d}$, the concentrations are much higher, i.e., about 2000 and $2600 \mathrm{mgCOD} / \mathrm{L} 22$ and $14^{\circ} \mathrm{C}$. The pattern here is important to note. The lower the influent flow, the higher the influent COD concentration for suspension mixing by the aeration system alone. For agro-industrial wastewaters, like those from fruit and vegetable processing, the influent COD concentrations are usually high (2 $000-3000 \mathrm{mgCOD} / \mathrm{L}$ ) and so suspension mixing by the aeration system alone can be achieved even at very low flows of $0.5 \mathrm{ML} / \mathrm{d}$ (Figs $7 \mathrm{a}$ and b). For municipal wastewater with low per capita water consumption, as is usual for rural areas, the raw wastewater influent COD concentrations are from $1000-1200 \mathrm{mgCOD} / \mathrm{L}$ (in South Africa), so the influent flow has to be quite high to achieve suspension mixing in the $1^{\text {st }}$ lagoon, i.e. $>2 \mathrm{ML} / \mathrm{d}$ at $22^{\circ} \mathrm{C}$ and $R_{\mathrm{h} 1}=1.0 \mathrm{~d}$ at $1000 \mathrm{mgCOD} / \mathrm{L}$ and $>3 \mathrm{ML} / \mathrm{d}$ at $14^{\circ} \mathrm{C}$ and $R_{\mathrm{h} 1}=1.5 \mathrm{~d}$ at $1050 \mathrm{mgCOD} / \mathrm{L}$ ). Because aerated lagoons are more likely to be applied in rural areas where land is more readily available, town populations are generally low (3000 to 10000 ), too low to generate a high influent flow. For example, a town with a population of 5000 at $0.1 \mathrm{kgCOD} /$ (person.d) produces an organic load of $500 \mathrm{kgCOD} / \mathrm{d}$. If the water contribution is, say, $100 \mathrm{~L} / \mathrm{d}$ per person, then the influent COD concentration and flow are 1 $000 \mathrm{mgCOD} / \mathrm{L}$ and $0.5 \mathrm{ML} / \mathrm{d}$. At a retention time of $1.5 \mathrm{~d}$ at $14^{\circ} \mathrm{C}$, the minimum influent COD concentration for suspension mixing by the aeration system alone is around $2600 \mathrm{mgCOD} / \mathrm{L}$. The minimum influent flow at $1000 \mathrm{mgCOD} / \mathrm{L}$ is about 3.0 $\mathrm{ML} / \mathrm{d}$ at $14^{\circ} \mathrm{C}$ and $R_{\mathrm{h} 1}=1.5 \mathrm{~d}$ giving a population of around 30 000. This is not a small town and it is probably better to build a normal AS system for it. Clearly, when treating municipal wastewater from small towns in aerated lagoons, the mixing energy of the aeration system in the 1st lagoon needs to be supplemented to ensure suspension mixing, making it unlikely that it will be applied due to the higher than normal activated sludge energy requirements (Fig 10).

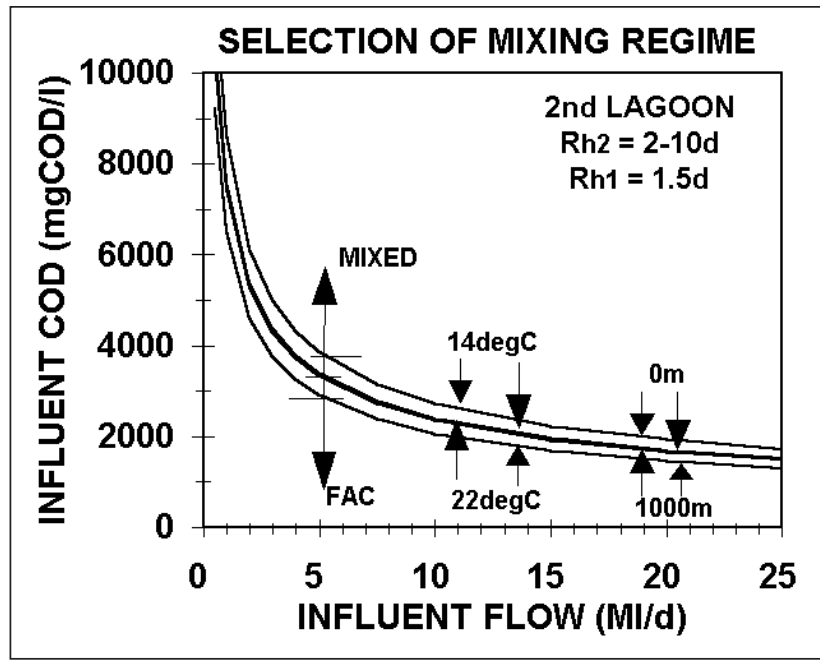

Figure 8

Influent $C O D$ concentration versus influent flow for facultative conditions in the $2^{\text {nd }}$ lagoon at retention times from $2-10 d$ with the $1^{\text {st }}$ lagoon retention time at $1.5 \mathrm{~d}$ for 14 and $22^{\circ} \mathrm{C}$ and 0 and $1000 \mathrm{~m}$ altitudes
For the $2^{\text {nd }}$ lagoon, the maximum influent COD concentration versus influent flow for facultative conditions is shown in Fig 8 for 14 and $22^{\circ} \mathrm{C}$, altitudes of 0 and $1000 \mathrm{~m}$ and a retention time of $1.5 \mathrm{~d}$ in the $1^{\text {st }}$ lagoon. From Fig. 8 it can be seen that:

- The higher the influent flow, the lower the influent COD concentration to ensure facultative conditions in the $2^{\text {nd }}$ lagoon.

- The higher the temperature and the higher the altitude, the lower the influent COD concentration to ensure facultative conditions in the $2^{\text {nd }}$ lagoon.

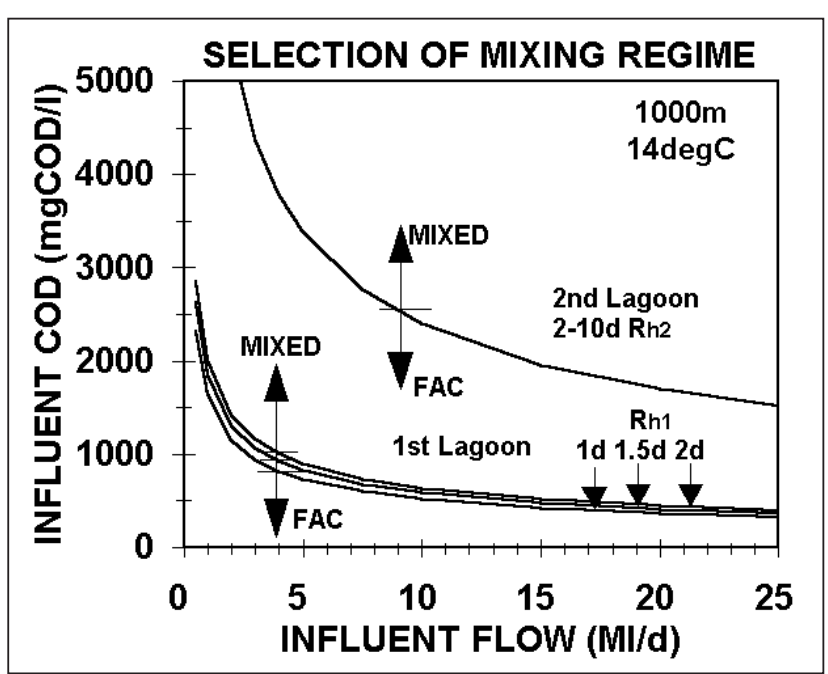

Figure 9

Influent $C O D$ concentration versus influent flow for suspension mixed conditions in the $1^{\text {st }}$ lagoon at retention times of 1.0, 1.5 and $2.0 \mathrm{~d}$ and facultative conditions in the $2^{\text {nd }}$ lagoon at retention times from 2-10 d $14^{\circ} \mathrm{C}$ and $1000 \mathrm{~m}$ altitude.

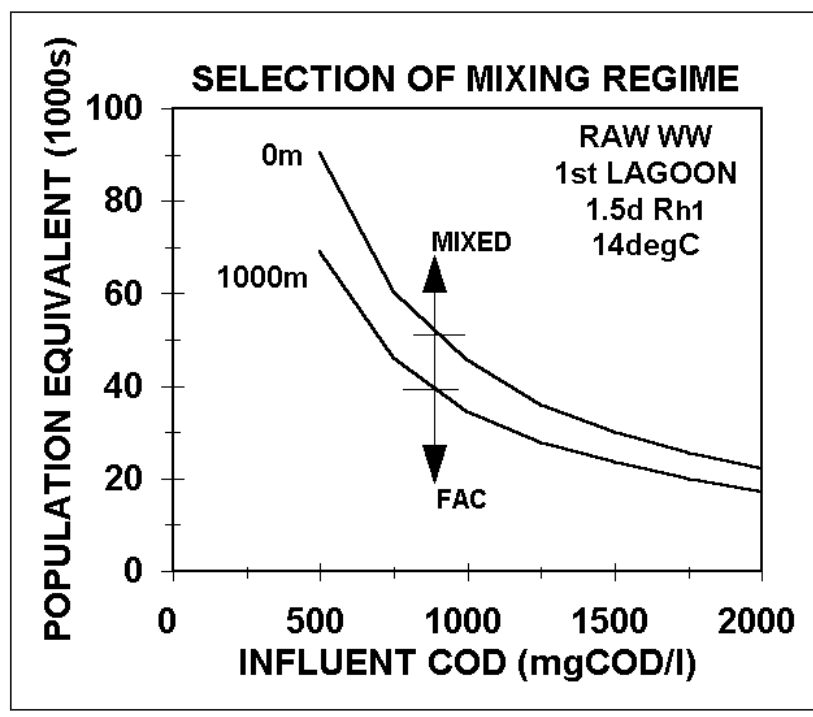

Figure 10

Population equivalent versus required average influent $C O D$ concentration to establish suspension mixing in the $1^{\text {st }}$ lagoon at $14^{\circ} \mathrm{C}$ by equating aeration and mixing energy requirements (lines) for $0 \mathrm{~m}$ and $1000 \mathrm{~m}$ ams/ showing that for small rural populations suspension mixing in the $1^{\text {st }}$ lagoon requires more energy than aeration. 
- Retention times in the $2^{\text {nd }}$ lagoon between 2 and $10 \mathrm{~d}$ do not affect the influent COD concentration and flow relationship.

An important conclusion from the above is that if high-strength agro-industrial wastewaters are treated in aerated lagoons, the influent flow must be low otherwise facultative conditions will not be achieved in the $2^{\text {nd }}$ lagoon. Without facultative conditions, settlement of solids will not take place and the effluent will have high $\mathrm{COD}, \mathrm{BOD}_{5}$ and suspended solids concentrations.

Combining the suspension and facultative mixing regime requirements for the $1^{\text {st }}$ and $2^{\text {nd }}$ lagoons defines lower and upper bounds for the influent COD concentration at different influent flows. This is shown in Fig. 9 (which is a combination of Figs $7 \mathrm{a}$ and 8 ). Proper operation of the lagoon system requires the influent COD concentrations above the $1^{\text {st }}$ lagoon lines to ensure suspension mixing in the $1^{\text {st }}$ lagoon and below the $2^{\text {nd }}$ lagoon line to ensure facultative conditions in the $2^{\text {nd }}$ lagoon. Influent COD concentration and flow values that fall midway in this band are best because the higher above the $1^{\text {st }}$ lagoon lines, the higher the mixing energy for suspension mixing and the lower below the $2^{\text {nd }}$ lagoon line, the lower the mixing energy for facultative conditions. Figure 9 is valid for $14^{\circ} \mathrm{C}$ and 1000 $\mathrm{m}$ altitude - higher temperatures and lower altitudes move the relative positions of the lines, but not by very much. However, these figures are not intended to be design charts but only to illustrate the principles involved in aerated lagoon process design. Influent COD concentration and flow combinations for suspension mixing in the $1^{\text {st }}$ lagoon and facultative conditions in the $2^{\text {nd }}$ lagoon will be affected significantly by different aeration system parameters to those in Table 3 , in particular the standard OTR $\left(R_{\mathrm{std}}\right)$ of the aeration device and the impurity correction factors for the oxygen mass transfer coefficient $K_{\text {La }}$ $(\alpha)$ and saturated DO concentration $(\beta)$. While the trends shown in Figs 7 to 9 are general and can be used for establishing the feasibility of treating a particular wastewater in an aerated lagoon system, it is recommended that detailed process design calculations are undertaken for each particular case using the equations developed in this paper. Furthermore, the lower and upper bounds for the influent COD concentration at different influent flows (Fig. 9) are based entirely on the premise that all the mixing energy is supplied by the aeration device. If the aeration mixing energy is supplemented, the lower bound on the $1^{\text {st }}$ lagoon will fall away. However, the upper bound on the $2^{\text {nd }}$ lagoon cannot fall away unless the aeration mixing energy can somehow be reduced without reducing the oxygen transfer. Finally, a matter of primary importance in design, but which is not addressed in this paper and therefore left to the expertise and experience of the design engineer, is how the aeration device's mixing energy is most effectively distributed into the lagoon volume - it is well known that different aeration devices have significantly different mixing efficiencies.

An alternative to the facultative lagoon is the facultative oxidation pond. Here it is difficult to determine a retention time. The fact that the pond receives organics (BOD) which are virtually all in a particulate solids form would aid settling of this material to the base of the pond. Probably, a pond of 5 to $7 \mathrm{~d}$ retention time, $1.5 \mathrm{~m}$ deep would be satisfactory. Balashi and Sperber (1975) report on the behaviour of such oxidation ponds. Effluent from a suspension mixed lagoon with 5 to $11 \mathrm{~d}$ retention time was discharged into an oxidation pond which was $60 \%$ of the volume of the aerated lagoon. The depth of the pond was 1 $\mathrm{m}$. Although an estimated $170 \mathrm{t}$ VSS mass was discharged to the oxidation pond over a period of 2 years, only $40 \mathrm{t}$ accumulation was measured in the sludge layer. No problems with odour development were noted. Based on this experience, it seems that a facultative pond following suspension mixed lagoons is also an appropriate method of wastewater treatment, particularly where space is not limiting.

\section{CONCLUSION}

The different kinds of aerated lagoons, which exclude anaerobic pre-treatment ponds, were described and the design approach for aerated lagoons was explained, viz., ensuring the $1^{\text {st }}$ lagoon is suspension mixed and the second is facultative. By careful selection of the hydraulic retention time (HRT) of the $1^{\text {st }}$ lagoon (HRTs calculated with the general activated sludge simulation model are given in the paper), it can be accepted that the influent biodegradable organics are completed utilized and transformed to $\mathrm{OHO}$ active VSS in the $1^{\text {st }}$ lagoon - it behaves very similarly to the single completely mixed AS system and the full growthendogenous respiration AS model is applied to the design of the $1^{\text {st }}$ lagoon. With no growth of OHO biomass in the $2^{\text {nd }}$ lagoon, it behaves similarly to the single or in-series reactor waste AS aerobic digester and only the endogenous respiration part of the model is applied to the design of the $2^{\text {nd }}$ (and additional) lagoons.

Even if biodegradation of the influent biodegradable organics is virtually complete in the $1^{\text {st }}$ lagoon, the COD removal is still low. This is because the AS formed in the $1^{\text {st }}$ lagoon is part of the unfiltered effluent COD because the lagoon is suspension mixed. In fact, the power input of the aeration system in the $1^{\text {st }}$ lagoon, sized to supply the growth and endogenous respiration oxygen demands, is usually sufficient for suspension mixing of high influent COD concentration agro-industry wastewaters. The filtered effluent COD is very low because (depending on the wastewater type and HRT) most of the influent soluble biodegradable organics are utilized and transformed to $\mathrm{OHO}$ VSS mass. In most wastewaters, including municipal wastewater, the soluble biodegradable organics are readily biodegradable and $\mathrm{OHO}$ mass is produced very rapidly from it. This $\mathrm{OHO}$ mass accelerates the utilization of the slowly biodegradable particulate organics, but that not utilized in the HRT of the $1^{\text {st }}$ lagoon is enmeshed with the AS and so is removable by settlement (or filtration) in the $2^{\text {nd }}$ lagoon. This is the main purpose of the $2^{\text {nd }}$ (and $3^{\text {rd }}$ ) facultative lagoon. In fact, the power input of the aeration system in the $2^{\text {nd }}$ (and $3^{\text {rd }}$ ) lagoon, sized to supply mainly the endogenous respiration oxygen demand, is usually insufficient for suspension mixing even though the oxygen demand in it is calculated assuming complete mixing. The unfiltered effluent COD from the $2^{\text {nd }}$ (and $3^{\text {rd }}$ ) lagoons is therefore mainly the COD of the remaining non-settleable AS (which is small) and the unbiodegradable soluble COD. The COD of filtered effluent is mainly the unbiodegradable soluble organics (USO).

Because selection of HRT of the $1^{\text {st }}$ lagoon is important to ensure complete utilization of the influent biodegradable organics, minimum retention times to achieve this at $14^{\circ} \mathrm{C}$ and $22^{\circ} \mathrm{C}$ were determined with the general AS kinetic simulation model UCTOLD (Dold et al., 1980, 1991) which gives identical results to Activated Sludge Model No 1 (ASM1, Henze et al., 1987; Dold and Marias, 1986) for (i) readily biodegradable soluble organics (BSO) only, slowly biodegradable particulate organics (BPO) only, real municipal wastewater (20\% BSO and $80 \% \mathrm{BPO}$ ) and real municipal wastewater with $5 \% \mathrm{OHO}$ active VSS mass seed. The minimum hydraulic retention times were found to be at $14^{\circ} \mathrm{C} 1.3,3.0,2.0$ and $1.5 \mathrm{~d}$, respectively, and at $22^{\circ} \mathrm{C} 0.3,2.0,1.2$ and $1.0 \mathrm{~d}$, respectively. From a comparison of 
the simulation results with the steady-state model calculations, washout of OHOs takes place at about $75 \%$ of these retention times.

Approximate equations to estimate the power requirements for aeration by mechanical surface aerators and mixing are given. These equations are combined with those of the steady-state AS model for calculating the oxygen requirements and the aeration power density $\left(\mathrm{W} / \mathrm{m}^{3}\right)$ in each lagoon. With these equations it is shown that influent COD concentration needs to be between an upper and lower limit band to ensure that the $1^{\text {st }}$ lagoon is suspension mixed and the second lagoon is facultative. This influent COD concentration band decreases as the influent flow increases, e.g., at $0.5 \mathrm{ML} / \mathrm{d}$ the influent COD needs to be between 2600 and $9000 \mathrm{mg} / \mathrm{L}$, but at $15 \mathrm{ML} / \mathrm{d}$ between 500 and $2000 \mathrm{mg} / \mathrm{L}$. The important conclusion arising from this is that if the aerated lagoon system is applied for small low-flow rural communities, where land for these large systems is likely to be available, then additional mixing energy over and above that required for aeration will need to be provided to ensure that the $1^{\text {st }}$ lagoon is suspension mixed. Due to the higher than normal activated sludge energy requirements this will necessitate, it is unlikely that aerated lagoons will be applied for treating municipal wastewater from small towns. Matching mixing and aeration power requirements is easier for agro-industrial organic wastewaters which usually have significantly higher influent organic strengths (COD) than municipal wastewaters.

\section{ACKNOWLEDGEMENTS}

This paper was commenced by Professor Gerrit van Rooyen Marais, Professor of Water Resources and Public Health Engineering at the University of Cape Town from 1967. He continued working on it after his retirement in 1992 with Professor Mark Wentzel but it remained unfinished at Mark Wentzel's permanent medical boarding in 2007 and Gerrit Marais' passing away in 2009. Working from their drafts and notes, I was able to finish it for publication.

\section{REFERENCES}

BALASHI E and SPERBER H (1975) Treatment of domestic wastes in an aerated lagoon and polishing pond. Water Rese. $943 \mathrm{https} / /$ doi, org/10.1016/0043-1354(75)90151-7

BEYCHOK MR (1971) Performance of surface aerated basins. Water 1970, Chem Eng Prog: Symposium Series, 67322.

DOLD P L, EKAMA G A and MARAIS GvR (1980) A general model for the activated sludge process. Prog. Wat. Tech. 12 (Toronto) 347-358.

DOLD P L and MARAIS GvR (1986) Evaluation of the general activated sludge model proposed by the IAWPRC task group. Wat. Sci. Technol. 18 (Copenhagen) 63-89.

DOLD P L, WENTZEL M C, BILLING A E, EKAMA G A and MARAIS GvR (1991) Activated sludge system simulation programs (Version 1.0). Water Research Commission, Private Bag X03, Gezina, 0031, South Africa.

ECKENFELDER WW (1966) Industrial Water Pollution Control. McGraw-Hill, New York.

EKAMA GA, WENTZEL MC and SÖTEMANN SW (2006) Mass balanced plant wide wastewater treatment plant models Part 2 Tracking the influent inorganic suspended solids. Water SA 32 (3) 277-285.

GLOYNA (1971) Waste Stabilisation Ponds. WHO monograph series No 60. WHO, Geneva.

HENZE M, GRADY C P L Jr, GUJER W, MARAIS GvR and MATSUO T (1987). Activated Sludge Model No.1. IAWQ Scientific and Technical Report No.1. IAWQ, London.
HENZE M, GUJER W, MINO T and VAN LOOSDRECHT MCM (2000). Activated Sludge Models Nos 1, 2, 2d and 3. IWA Scientific and Technical Report No 9. IWA, London. ISBN 1900 222248. 121 pp.

HENZE M, VAN LOOSDRECHT MCM, EKAMA GA and BRDJANOVIC D (2008) Biological Wastewater Treatment - Theory, Modelling and Design. IWA Publishing, London, UK. ISBN 13: 9781843391883.

MARAIS GvR (1966) New factors in the design, operation and performance of waste stabilisation ponds. Bull. WHO. 34, 737-763.

MARAIS GvR (1970) Dynamic behaviour of oxidation ponds. 2nd Intnl Symp on Waste Treatment in Lagoons, Kansas City.

MARAIS GvR and EKAMA GA (1976) The activated sludge process Part 1 - Steady state behaviour. Water SA 2(4) 163-200.

PHELPS EB (1944) Stream Sanitation. John Wiley \& Sons, New York.

VON DER EMDE W (1969) Entwurf Beluftungssysteme, Wiener Mitteilungen, 4, Abwasserreinigungsanlagen - Entwurf, Bau, Betrieb, Vienna.

WPCF/ASCE (1988) Aeration - Manual of Practice FD-13, Water Pollution Control Federation, ASCE Manuals and Reports on Engineering Practice No. 68. American Society of Civil Engineers, Reston VA.

WRC (Water Research Commission, South Africa) (1984) Theory, design and operation of biological nutrient removal activated sludge systems. (Ed.: Wiechers HNS). WRC Report No. TT16/84, Water Research Commission, Pretoria. ISBN 0908356137.

\section{APPENDIX 1}

\section{Modelling the BOD test with the activated sludge model}

Relationships for the $\mathrm{COD} / \mathrm{BOD}_{5}$ ratio at different stages of biological treatment are derived below with the aid of the AS theory set out by Marais and Ekama (1976). The COD/BOD 5 is required to recast the COD-based steady-state AS model into $\mathrm{BOD}_{5}$ terms for design of aerated lagoons, which have a long history based on $\mathrm{BOD}_{5}$.

Accepting the wastewater organics (COD) fractionation into soluble and particulate and biodegradable and unbiodegradable fractions, the biodegradable COD of influent wastewater $\left(S_{\mathrm{bi}}\right)$ in terms of the total COD $\left(S_{\mathrm{ti}}\right)$ is given by Eq. 1 in the paper.

In the BOD bottle, the biodegradable organics $\left(S_{\mathrm{bi}}\right)$ are all utilized by the ordinary heterotrophic organism (OHO) seed and metabolized into active $\mathrm{OHO}$ mass. The oxygen utilized and the $\mathrm{OHO}$ biomass formed in the catabolism and anabolism parts of the metabolic growth process are given by Marais and Ekama (1976) as:

$O_{s}=\left(1-f_{c v} Y_{H}\right) S_{b i} \mathrm{mgO} / \mathrm{L}$

$X_{B H}=Y_{H} S_{b i} \mathrm{mgVSS} / \mathrm{L}$

where:

$Y_{H}=\mathrm{OHO}$ yield coefficient $=0.45 \mathrm{mgVSS} / \mathrm{mgCOD}$

$f_{c v}=\mathrm{COD} / \mathrm{VSS}$ ratio of the OHO biomass $=1.48 \mathrm{mgCOD} /$ mgVSS

The COD/VSS ratio of 1.48 was found from many years of experimental work with AS systems treating real municipal wastewater and is the default value in the IWA ASMs (Henze et al., 2000).

After growth of the $\mathrm{OHO}$ biomass, it undergoes endogenous respiration as outlined by Marais and Ekama (1976). The oxygen utilization rate for endogenous respiration is given by their Eq. 20 , i.e.:

$\frac{d o_{e}}{d t}=f_{c v}\left(1-f_{H}\right) b_{H T} X_{B H t} \mathrm{mgO} /(\mathrm{L} . \mathrm{d})$ 
where:

$f_{H}=$ unbiodegradable fractions of OHO VSS mass

$b_{H T}=$ specific endogenous respiration rate at $\mathrm{T}^{\circ} \mathrm{C}$

The specific endogenous respiration rate, $b_{\mathrm{H}}$, was measured in batch aerobic digestion tests by Marais and Ekama (1976) and confirmed by Ekama et al. (2006). It was found to be independent of sludge age of the AS system but slightly sensitive to temperature, viz.:

$b_{H T}=b_{H 20}(1.029)^{(T-20)} / \mathrm{d}$

where:

$b_{H 20}=$ specific endogenous respiration rate at $20^{\circ} \mathrm{C}=0.24 / \mathrm{d}$

In the endogenous respiration process, the OHO VSS concentration $X_{\mathrm{BH}}$ declines with time at the $1^{\text {st }}$ order $b_{\mathrm{H}}$ rate and generates an unbiodegradable particulate endogenous residue $X_{\mathrm{E}}$, i.e.:

$\frac{d X_{B H}}{d t}=-b_{H T} X_{B H} \mathrm{mgVSS} /(\mathrm{L} . \mathrm{d})$

Integrating Eq. A5 over time yields the OHO VSS concentration time at under batch test conditions, i.e.:

$X_{B H t}=X_{B H i} e^{-b_{H} t} \mathrm{mgVSS} / \mathrm{L}$

Substituting Eq. A6 into Eq. A3 and integrating again yields the cumulative oxygen utilized for endogenous respiration $O_{\text {et }}$ after time $t$, i.e.:

$\int_{0}^{t} \frac{d O_{e}}{d t}=f_{c v}\left(1-f_{H}\right) b_{H T} X_{B H i} \int_{0}^{t} e^{-b_{H T} t} \mathrm{mgO} /($ L.d $)$

and accepting $O_{\mathrm{e}}=0$ at time $t=0$, yields:

$O_{e t}=f_{c v}\left(1-f_{H}\right) X_{B H i}\left(1-e^{-b_{H T} t}\right) \mathrm{mgO} / \mathrm{L}$

Adding to this the catabolic growth oxygen demand, $O$ (Eq. A1), which assumes growth is instantaneous, yields the cumulative carbonaceous oxygen demand at time $t$ days $\left(O_{c t}\right)$, which is the theoretical BOD at time $t$, i.e.:

$\mathrm{BOD}_{t}=O_{c t}=O_{s}+O_{e t}=\left(1-f_{c v} Y_{H}\right)$

$S_{b i}+f_{c v}\left(1-f_{H}\right) X_{B H i}\left(1-e^{-b_{H T} t}\right) \mathrm{mgO} / \mathrm{L}$

Substituting Eq. A2 for $X_{B H i}, 5 \mathrm{~d}$ and infinity for $t$ yields the $\mathrm{BOD}_{5}, \mathrm{BOD}_{u}$ and their ratio:

$\mathrm{BOD}_{5}=S_{b i}\left[\left(1-f_{c v} Y_{H}\right)+f_{c v}\left(1-f_{H}\right) 0.70\right]=$

$0.707 S_{b i} \mathrm{mgBOD}_{5} / \mathrm{L}$

$\mathrm{BOD}_{u}=S_{b i}\left[\left(1-f_{c v} Y_{H}\right)+f_{c v}\left(1-f_{H}\right) 1.0\right]=0.867 S_{b i} \mathrm{mgBOD}_{u} / \mathrm{L}$

$\frac{B O D_{5}}{B O D_{u}}=\frac{0.707}{0.867}=0.815$

Substituting the total COD $S_{t i}$, yields for the $\mathrm{BOD}_{5}$

$\mathrm{BOD}_{5}=S_{t i}\left(1-f_{S^{\prime} u p}-S_{S^{\prime} u s}\right) 0.707 \mathrm{mgBOD} / \mathrm{L}$

and hence the theoretical approximation of $\mathrm{COD} / \mathrm{BOD}_{5}$ ratio based on the steady-state AS model is:
$\frac{\mathrm{COD}}{\mathrm{BOD}_{5}}=\frac{1.41}{\left(1-f_{S^{\prime} u S^{-}}-f_{S^{\prime} u p}\right)} \mathrm{mgCOD} / \mathrm{mgBOD}_{5}$

From the Phelps (1944) empirical relationship for the BOD time curve (see Fig. A1), i.e.:

$\mathrm{BOD}_{t}=\mathrm{BOD}_{u}\left(1-e^{-K t}\right) \mathrm{mgBOD}_{\mathrm{t}} / \mathrm{L}$

where $K=0.23 / \mathrm{d}$ at $20^{\circ} \mathrm{C}$.

allows a relationship to be made between the $\mathrm{BOD}_{5}$ and the ultimate $\mathrm{BOD}\left(\mathrm{BOD}_{\mathrm{u}}\right.$ at $\left.20 \mathrm{~d}\right)$, i.e.:

$\mathrm{BOD}_{5}=0.68 \mathrm{BOD}_{u} \mathrm{mgBOD} / \mathrm{L}$

The similarity at $20^{\circ} \mathrm{C}$ between the Phelps $\mathrm{K}(0.23 / \mathrm{d})$ and the endogenous respiration rate $(0.24 / \mathrm{d})$ of the growth-endogenous respiration model confirms this approach to modelling the BOD test.

Taking the example raw and settled wastewater (WW) values for $f_{\text {S us }}$ and $f_{\text {S up }}$ given in WRC (1984), i.e. Raw WW: $f_{\text {Sus }}=0.07$, $f_{\text {Sup }}=0.15$ and Settled WW: $f_{\text {Sus }}=0.117, f_{\text {Sup }}=0.04$, yields COD/ $\mathrm{BOD}_{5}$ ratios of 1.81 and 1.67 respectively from Eq. A13. The settled wastewater value is considerably lower than the measured mean values given for settled wastewater by Marais and Ekama (1976). Combining Eq. A11 for BOD with Eq. A15 of Phelps for the $\mathrm{BOD}_{5} / \mathrm{BOD}_{4}$ ratio yields $\mathrm{COD} / \mathrm{BOD}_{5}$ ratios of 2.17 and 2.01 for the example raw and settled wastewaters, respectively. The raw wastewater value is reasonably close to the 2.1 value often used in South Africa for the COD/BOD 5 ratio for raw wastewater, and the settled wastewater value is close to the values reported by Marais and Ekama (1976) in their Table 2. Thus, the assumption in Eq. A10, that $\mathrm{OHO}$ growth is instantaneous, does not appear valid.

Plotting the theoretically calculated BOD time curves with the steady-state (Eq. A9) and general AS models such as UCTOLD (Dold et al., 1980; 1991) or IWA ASM No1 (Henze et al., 1987) provides further evidence for the validity of the above approach for calculating the $\mathrm{COD} / \mathrm{BOD}_{5}$ ratio with the AS model. Figures A2 and A3 show the BOD time curves for the example raw wastewater calculated from (1) the steadystate AS model (Eq. A9) assuming growth of OHO mass is (1.1) instantaneous and (1.2) complete after $48 \mathrm{~h},(2)$ the general AS model, which makes a distinction between rate of utilization of readily biodegradable soluble organics (BSO) and slowly biodegradable particulate organics (BPO) and (3) the empirical Eq. A14 of Phelps (1944). For the general AS model line, the default kinetic and stoichiometric constants were used and the OHO seed (as COD) was $2 \%$ of the influent COD.

Comparing Figs A1 and A2 with Fig. A3, which shows a typical experimentally observed BOD time curve and the Phelps' Eq. A14, the following can be noted:

1. The $\mathrm{BOD}$ is predicted to be virtually the same for all four methods, i.e., about $510 \mathrm{mg} / \mathrm{L}$ for the $750 \mathrm{mgCOD} / \mathrm{L}$ example raw wastewater.

2. The $\mathrm{BOD}_{5}$ for the steady-state AS model methods are closely similar, i.e., about $410 \mathrm{mg} / \mathrm{L}$, which is about $80 \%$ of the $\mathrm{BOD}$. This is somewhat higher than the Phelps Eq. $\mathrm{A} 14$ predicted $\mathrm{BOD}_{5}$, which is $68 \%$ of the $\mathrm{BOD}_{u}$, i.e. 345 $\mathrm{mg} / \mathrm{L}$. From Fig A3, the experimentally observed $\mathrm{BOD}_{5} /$ $\mathrm{BOD}$ ratio also is around $80 \%(185 / 230)$, which is higher than the Phelps value of $68 \%(157 / 230)$. Therefore, the AS model estimates of the BOD time curve appear closer to that experimentally observed than the Phelps equation, but 
the difference is small: If the $\mathrm{BOD}_{u}$ in Fig A3 is $250 \mathrm{mg} / \mathrm{L}$ instead of $230 \mathrm{mg} / \mathrm{L}$, the Phelps equation cuts through the experimentally observed $\mathrm{BOD}_{5}=185 \mathrm{mg} / \mathrm{L}$ point $(185 / 250$ $=0.74)$. However, as noted above the steady-state AS model estimates for the $\mathrm{BOD}_{5} / \mathrm{BOD}_{\mathrm{u}}$ ratio do give $\mathrm{COD} / \mathrm{BOD}_{5}$ ratios that are higher than observed values (Table 2 in Marais and Ekama, 1976), and those implemented in practice.

3. Figure $\mathrm{A} 2$ shows an initial lag in the $\mathrm{BOD}$ time response and then a rapid increase with a plateau at $\sim 1.5 \mathrm{~d}$. The general AS model (Fig. A2) shows a similar response. In the model, the initial lag is due to the very low initial seed $\mathrm{OHO}$ concentration ( $3 \%$ of total COD). Because growth on readily $\mathrm{BSO}$ is rapid, the $\mathrm{OHO}$ concentration rapidly increases and causes the sharp increase in BOD. After $\sim 0.65 \mathrm{~d}$, the BSO is all utilized but growth continues on the slowly BPO, which stops at $\sim 1.5 \mathrm{~d}$. Although the specific $\mathrm{OHO}$ growth rate on BPO is about $1 / 10^{\text {th }}$ of that on BSO, after $0.65 \mathrm{~d}$, the actual $\mathrm{BPO}$ utilization rate is reasonably high because the $\mathrm{OHO}$ concentration has increased due to the rapid growth on BSO. Therefore, the BOD continues to increase steeply while utilizing the BPO. Once the BPO is completely utilized at

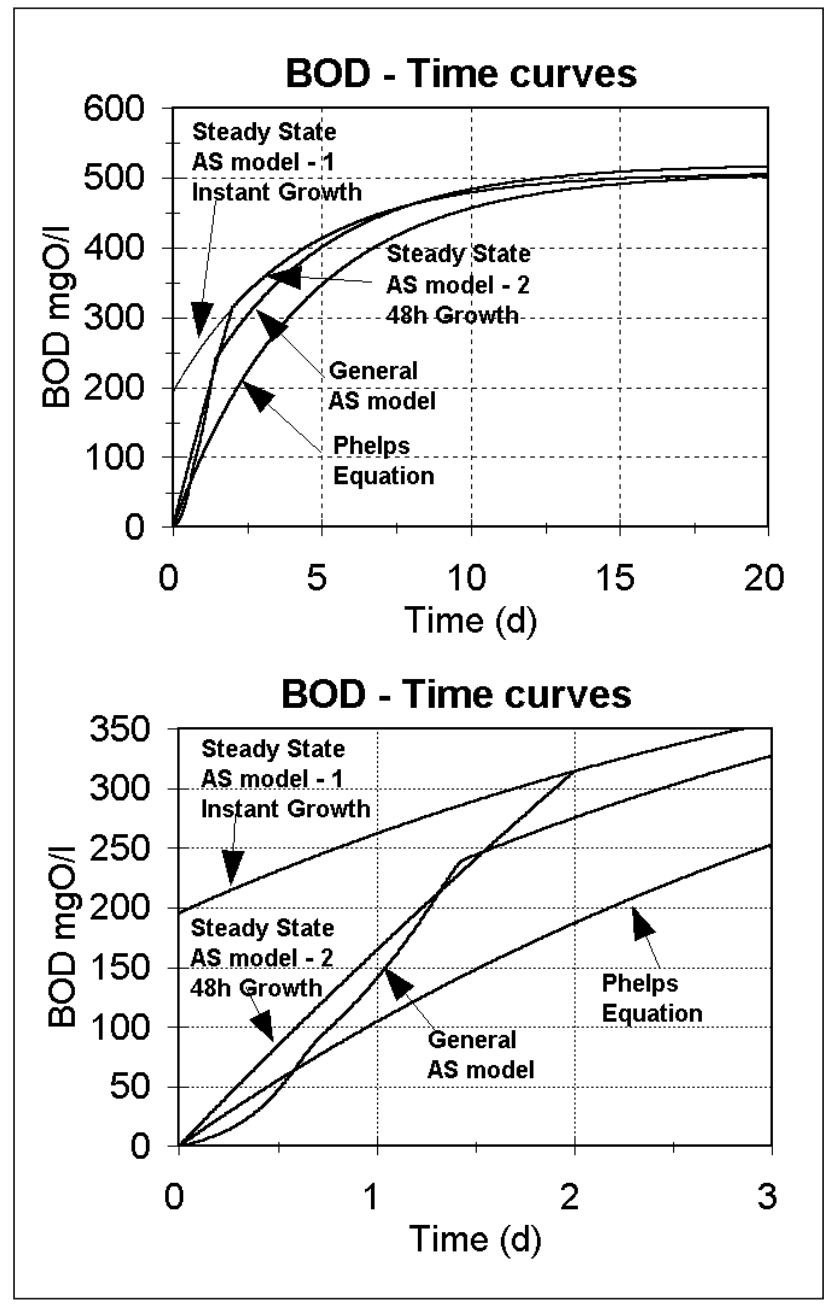

Figure $A 1$ and $A 2$

Cumulative oxygen utilized (BOD)-time curves at $20^{\circ} \mathrm{C}$ for the example raw wastewater, calculated with the steady-state activated sludge (AS) model assuming $\mathrm{OHO}$ growth is (1) instantaneous and (2) takes $48 \mathrm{~h}$, the general AS model and the Phelps (1944) empirical equation (Eq. A15) over $20 d$ (Fig. A1, top) and $3 d$ (Fig. A2) to show more detail at the start. $\sim 1.5 \mathrm{~d}$, OHO growth ceases and the BOD increases much more slowly due to the slow endogenous process. The delay of $1.5 \mathrm{~d}$ in complete BPO utilization causes the OUR associated with the endogenous process also to be delayed (shift to the right in Fig. A1), giving a $\mathrm{BOD}_{5}$ value of about $392 \mathrm{mg} / \mathrm{L}$ which is $77 \%$ of the $\mathrm{BOD}_{u}$. Thus, the general model $\mathrm{BOD}_{5} / \mathrm{BOD}_{u}$ ratio (0.77) lies between that of the steady-state AS models (0.80) and that of Phelps (0.68), and illustrates the uncertainty in this value.

The above discussion demonstrates that the AS models simulate the BOD time curve reasonably well. While the general model simulates it better than the steady-state model, the latter nevertheless gives a reasonable $1^{\text {st }}$ estimate of $\mathrm{COD} / \mathrm{BOD}_{5}$ ratio; this can be refined from the $\mathrm{BOD}_{5} / \mathrm{BOD}_{u}$ ratio of Phelps (as demonstrated above), or from that of the general AS model. The relationships developed above therefore can be used when converting from $\mathrm{COD}$ to $\mathrm{BOD}_{5}$ units.

\section{APPENDIX 2}

\section{List of symbols and abbreviations}

\section{List of symbols}

a oxygen transfer rate $\left(K_{L a}\right)$ correction term for impurities $\beta \quad$ DO saturation concentration correction term for impurities

$\gamma \quad \mathrm{COD}$ to $\mathrm{BOD}_{5}$ conversion factor

$\theta \quad$ oxygen transfer rate $\left(K_{L a}\right)$ correction term for temperature

$b_{\mathrm{H}} \quad \mathrm{OHO}$ endogenous respiration rate. Additional subscript $\mathrm{T}$ or 20 denotes $\mathrm{T}$ or $20^{\circ} \mathrm{C}$

$\mathrm{BOD}_{5 \mathrm{i}}$ influent $\mathrm{BOD}_{5}$ concentration $(\mathrm{mgO} / \mathrm{L})$

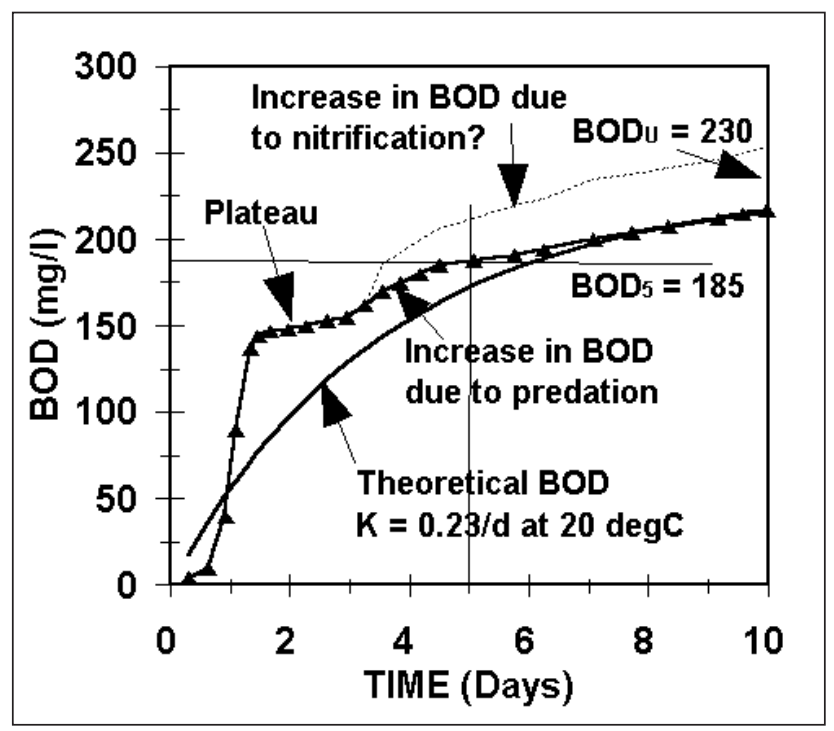

\section{Figure $\mathbf{A} 3$}

Typical experimental BOD time curve on wastewater sample with heterogeneous seed clearly showing the 'plateau' behaviour after about $1.5 \mathrm{~d}$ followed by an increase in oxygen utilized considered to be due to predation (Copcutt, 1983). Nitrification, which can occur from about $5 d$ unless inhibited by ATU, can cause a second increase in BOD. The theoretical BOD time curve with Phelps' (1944) $K=0.23 / \mathrm{d}$ at $20^{\circ} \mathrm{C}$ also is shown for an ultimate $B O D_{\mathrm{U}}=230 \mathrm{mg} / \mathrm{L}$. 
$\mathrm{BOD}_{5 \mathrm{n}}$ unfiltered $\mathrm{BOD}_{5}$ concentration in and exiting $n^{\text {th }}$ lagoon $(\mathrm{mgO} / \mathrm{L})$

$\mathrm{BOD}_{5 \mathrm{fn}}$ filtered $\mathrm{BOD}_{5}$ concentration in and exiting $n^{\text {th }}$ lagoon $(\mathrm{mgO} / \mathrm{L})$

$\triangle \mathrm{BOD}_{5}$ change in $\mathrm{BOD}_{5}$ concentration (influent minus effluent) $(\mathrm{mgO} / \mathrm{L})$

$C_{\mathrm{L}} \quad$ DO concentration in lagoon $(\mathrm{mgO} / \mathrm{L})$

$C_{\text {Sstd }} \quad$ saturation DO coentration under standard (STP) conditions

$f_{\mathrm{cv}} \quad \mathrm{COD} / \mathrm{VSS}$ ratio of infl;uet UPO and OHO biomass = $1.48 \mathrm{mgCOD} / \mathrm{mgVSS}$

$f_{\mathrm{H}} \quad$ unbiodegradable fraction of $\mathrm{OHO}$ biomass $=0.20$ $\mathrm{mgVSS} / \mathrm{mgOHOVSS}$

$\mathrm{FO}_{\text {cn }} \quad$ flux oxygen demand $(\mathrm{kgO} / \mathrm{d})$ required for organics removal in $\mathrm{n}^{\text {th }}$ lagoon

$f_{\text {Sup }} \quad$ unbiodegradable particulate organics (USO) fraction of total COD

$f_{\text {Sus }}$ unbiodegradable soluble organics (UPO) fraction of total COD concentration

$K$ substrate utilization rate in the BOD time equation of Phelps (1944)

$K_{\mathrm{La}} \quad$ oxygen mass transfer coefficient (/d)

$K_{\mathrm{v}} \quad$ substrate utilization rate in VSS and COD units. Additional subscript T or 20 denotes $\mathrm{T}$ or $20^{\circ} \mathrm{C}$

$K_{\mathrm{vB}} \quad$ substrate utilization rate in VSS and $\mathrm{BOD}_{5}$ units. Additional subscript $\mathrm{T}$ or 20 denotes $\mathrm{T}$ or $20^{\circ} \mathrm{C}$

$M X_{\mathrm{BHn}}$ mass $\mathrm{OHO}$ biomass in $\mathrm{n}^{\text {th }}$ lagoon (kgOHOVSS)

$\mathrm{O}_{c} \quad$ oxygen utilization rate for organic removal $[\mathrm{mgO} /(\mathrm{l} \cdot \mathrm{d})]$. Additional subscript $t$ denotes rate at time $t$

$\mathrm{O}_{\mathrm{e}} \quad$ oxygen utilization rate for endogenous respiration $[\mathrm{mgO} /(\mathrm{l} \cdot \mathrm{d})]$. Additional subscript $\mathrm{t}$ denotes rate at time $\mathrm{t}$

$\mathrm{O}_{\mathrm{s}} \quad$ oxygen utilization rate for $\mathrm{OHO}$ growth (catabolism) $[\mathrm{mgO} /(\mathrm{l} \cdot \mathrm{d})]$

$p_{20} \quad$ saturation vapour pressure for water at $20^{\circ} \mathrm{C}(\mathrm{mmHg})$

$p_{\text {act }} \quad$ saturation vapour pressure for water at site temperature $(\mathrm{mmHg})$

$P_{\text {act }} \quad$ atmospheric pressure under site conditions $(\mathrm{mmHg})$

$P_{\mathrm{dn}}^{\text {act }} \quad$ power density for aeration in $n^{\text {th }}$ lagoon $\left(\mathrm{W} / \mathrm{m}^{3}\right)$

$P_{n}^{\mathrm{dn}} \quad$ power requirement for aeration in $n^{\text {th }}$ lagoon $(\mathrm{kW})$

$p_{\text {std }} \quad$ saturation vapour pressure for water at standard temperature $(\mathrm{mmHg})$

Pstd atmospheric pressure under standard (STP) conditions (mmHg)

$Q_{i} \quad$ influent flow rate $(\mathrm{ML} / \mathrm{d})$

$R_{\text {act }} \quad$ oxygen transfer rate under site conditions

$R_{\mathrm{hn}} \quad$ hydraulic retention time (HRT) of the $n^{\text {th }}$ lagoon. Subscript min denotes minimum.

$R_{\mathrm{s}} \quad$ sludge age or solids retention time (SRT) in days

$R_{\mathrm{std}} \quad$ oxygen transfer rate under standard (STP) conditions influent biodegradable COD concentration residual biodegradable COD concentration exiting $n^{\text {th }}$ lagoon

$S_{\text {tfin }} \quad$ filtered COD concentration exiting $n^{\text {th }}$ lagoon.

$S_{\text {ti }} \quad$ influent total COD concentration

$S_{\text {tn }} \quad$ unfiltered COD concentration exiting $n^{\text {th }}$ lagoon

$S_{\text {upi }} \quad$ influent unbiodegradable particulate organics (UPO) COD concentration

$S_{\text {usi }} \quad$ influent unbiodegradable soluble organics (USO) COD concentration

$S_{\text {usn }} \quad$ unbiodegradable soluble organics (USO) COD concentration exiting $n^{\text {th }}$ lagoon

$t \quad$ time

$T \quad$ Temperature in ${ }^{\circ} \mathrm{C}$

$V \quad$ volume of $n^{\text {th }}$ lagoon $\left(\mathrm{m}^{3}\right)$

$X_{\mathrm{En}}^{\mathrm{n}} \quad$ concentration of $\mathrm{OHO}$ endogenous residue in $n^{\text {th }}$ lagoon (mgVSS/L)

$X_{\mathrm{Ii}} \quad$ influent unbiodegradable particulate organics (UPO) VSS concentration

$X_{\mathrm{In}} \quad$ concentration of UPO exiting $n^{\text {th }}$ lagoon $(\mathrm{mgVSS} / \mathrm{L})$

$X_{\mathrm{vn}} \quad$ concentration of $\mathrm{OHO}$ biomass in and exiting $n^{\text {th }}$ lagoon (mgOHOVSS/L)

$Y_{\mathrm{H}} \quad$ OHO yield coefficient $=0.45 \mathrm{mgOHOVSS} / \mathrm{mgCOD}$

$Y_{\mathrm{HB}} \quad \mathrm{OHO}$ yield coefficient in terms of $\mathrm{BOD}_{5}=\gamma 0.45$ $\mathrm{mgOHOVSS} / \mathrm{mgBOD}_{5}$

\section{List of Abbreviations}

AS activated sludge

ASM1 Activated Sludge Model No 1

$\mathrm{BOD}_{5} 5$ day biochemical oxygen demand

BOD $_{u}$ ultimate (20d) biochemical oxygen demand

BPO biodegradable particulate organics

BSO biodegradable soluble organics

COD chemical oxygen demand

DO dissolved oxygen

$\mathrm{N}$ nitrogen

OD oxygen demand

OHO ordinary heterotrophic organisms

OTR oxygen transfer rate

P phosphorus

SS steady state

STP standard temperature $\left(20^{\circ} \mathrm{C}\right)$ and pressure $(1 \mathrm{~atm}=760$ $\mathrm{mmHg}$ )

TKN total Kjeldahl nitrogen

UPO unbiodegradable particulate organics

USO unbiodegradable soluble organics

VSS volatile suspended solids

WW wastewater 